
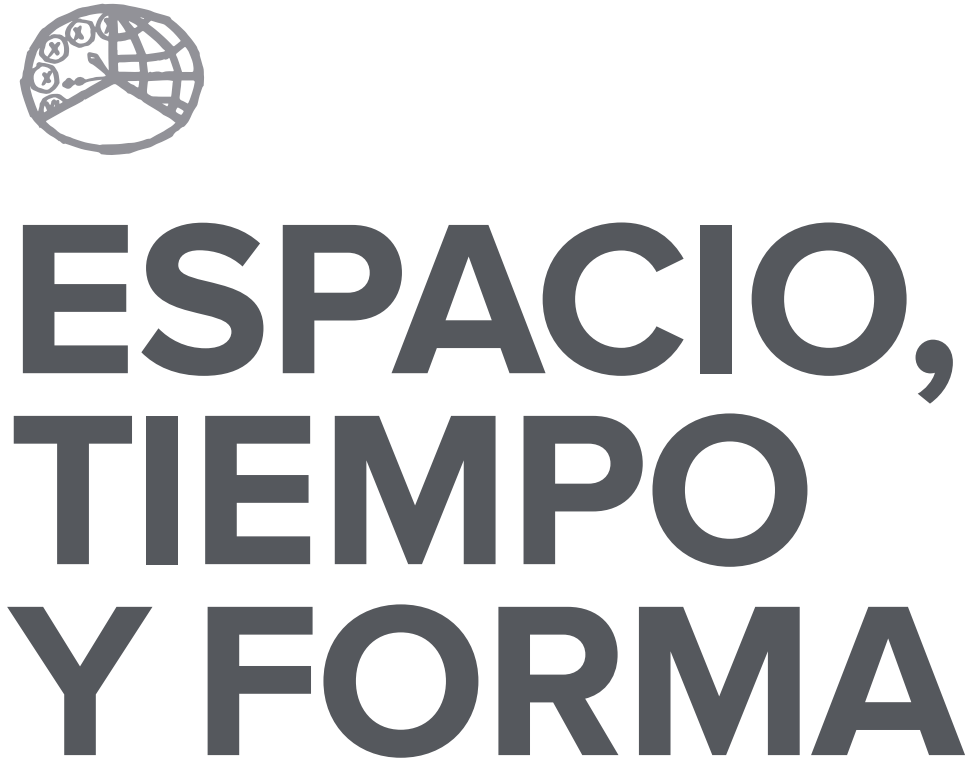

AÑO 2018

ISSN 0214-9745

E-ISSN 2340-1362

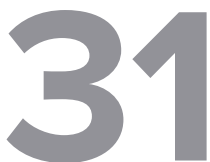

SERIE III HISTORIA MEDIEVAL

REVISTA DE LA FACULTAD DE GEOGRAFÍA E HISTORIA 



\section{ARTÍCULOS · ARTICLES}





\title{
EL CÓDICE VISIGÓTICO DE LOS MORALIA IN IOB, MS. LAT. 83 DE LA JOHN RYLANDS LIBRARY DE MANCHESTER
}

\section{A VISIGOTHIC CODEX OF THE MORALIA IN IOB, MS. LAT. 83 OF THE JOHN RYLANDS LIBRARY AT MANCHESTER}

\author{
Paloma Cuenca Muñoz ${ }^{1}$
}

Recepción: 2017.6.30 • Comunicación de observaciones de evaluadores: 2017.10.19 •

Aceptación: 2017.10.26

DOI: http://dx.doi.org/10.5944/etfiii.31.2018.21157

\section{Resumen}

El presente trabajo aborda el análisis del manuscrito Ms. Lat. 83 que contiene la obra de san Gregorio Magno Moralia in Iob custodiado en la John Rylands Library de Manchester. Se trata de uno de los escasos códices conservados en escritura visigótica. Hasta la actualidad el único estudio monográfico existente proponía un análisis paleográfico y codicológico cuya revisión, aplicando la metodología paleográfica actual, ha dado lugar a numerosos cambios y nuevas propuestas, entre las que destacan una diferente actuación de los copistas que intervienen en el códice y por lo tanto, una nueva visión sobre la génesis de dicho manuscrito.

\section{Palabras clave}

Paleografía; codicología; escritura visigótica; códice medieval; libros morales de san Gregorio; Gómez, copista.

\section{Abstract}

This paper focuses on the analysis of the manuscript Ms. Lat. 83 containing the work of St. Gregory the Great, Moralia in Iob, found at the John Rylands Library at Manchester. It is one of the few extant codices in Visigothic writing. Until now,

1. Departamento de Ciencias y Técnicas Historiográficas de la Universidad Complutense de Madrid. C.e.:palomacm@ghis.ucm.es 
the only existing monographic study proposed a paleographic and codicological analysis. By applying current paleographic methodology we will propose changes and new proposals, of which we can highlight the different performance of the copyists who intervene in the codex and, therefore, present a new vision on the genesis of this manuscript.

\section{Keywords}

Paleography; Codicology; Visigothic Writing; Medieval Codex; Moral Books of St. Gregory; Gómez, the Copyist.

Los XXXV libros morales que escribiera san Gregorio en Constantinopla entre los años 579 y $602^{2}$, son revisados y adquieren una nueva forma cuando se dividen sus libros en seis partes y se les añade un conjunto introductorio de opúsculos a modo de prolegómeno de la obra gregoriana. Las fechas propuestas para esta inserción inicial de textos ${ }^{3}$ tiene como como términos los años transcurridos entre 754 y 9I4, puesto que incluyen un fragmento de la crónica Mozárabe realizada en dicho año y la primera copia conocida que transmite dicha tradición textual es una copia de la obra gregoriana del año 9I4, realizada por un copista denominado Gómez en el escritorio de san Pedro de Cardeña.

Se trata de un texto muy difundido durante la Edad Media, como queda demostrado con el catálogo incompleto de testimonios conservados que realiza $M$. Adriaen, donde quedan recogidos más de quinientos códices escritos entre los siglos VII/VIII al XV4. En concreto, dentro de la tradición hispánica se conserva un número importante de manuscritos, custodiados tanto en bibliotecas españolas como extranjeras, que, copiados en escritura visigótica, suponen los primeros ejemplos de la mencionada tradición textual gregoriana.

En el presente estudio se va a analizar el trabajo que Gómez finalizara en el año 9I4, que además de poseer especial importancia desde el ámbito de la crítica especializada, por su compleja tradición textual, resulta ser uno de los escasos testimonios que conforman el actual corpus de códices realizados en escritura visigótica5.

2. La edición de esta obra que cuenta con un estudio introductorio y una moderna fijación textual es la llevada a cabo por Adriaen, Marci, S. Gregorii Magni, Moralia in lob, Serie Latina, 143, 143A, 143B Turnhout, Brepols, 1979-1985, 3 v. No obstante para citas concretas del texto también he utilizado la edición mucho más accesible de MiGNE, J. P., Patrologia Latina, vol. 76 .

3. Sobre el proceso de ensamblaje de los diferentes textos introductorios y sus posibles fechas, véase Díaz y Díaz, Manuel Cecilio., Libros y librerías en la Rioja altomedieval, Logroño, 1991², p. 126.

4. Adriaen, Marci, op. cit., pp. XIV-XXIX.

5. Véase Millares Carlo, Agustín, Corpus de códices visigóticos, Gobierno de Canarias, 1999, v. 1, n. 219, p. 147. 
A la descripción que de este códice realiza F. Berganza debemos algunos datos de difícil constatación, ya que en ocasiones se refieren a partes del manuscrito que él aseguró ver, pero que en la actualidad no se conservan ${ }^{6}$. No obstante, a partir de los datos de los investigadores que, de un modo y otro, han publicado diferentes aportaciones sobre este códice, se hace necesaria una revisión que pueda dar cuenta de nuevas observaciones paleográficas y codicológicas, con la ayuda inestimable que presentan las nuevas tecnologías.

\section{DESCRIPCIÓN CODICOLÓGICA DEL MS. LAT. 83}

Es necesario tener en cuenta diferentes cuestiones al abordar la descripción de los aspectos materiales del códice, entre otros motivos que hacen referencia a las particularidades del códice, porque no se ha conservado completo. Hasta nosotros ha llegado gran parte de los folios que compusieron el manuscrito original, pero en diferentes estados de conservación y con intervenciones posteriores que han dejado marcas, tanto en los aspectos externos del manuscrito como en sus características intrínsecas.

Por lo que se refiere a la confección de los cuadernos, del códice inicial se han perdido los primeros siete cuadernos completos, más seis folios del octavo, así como un número indeterminado de los folios finales. En cuanto a la parte del manuscrito que se conserva está compuesta por el último bifolio del cuaderno VIII, además de 43 fascículos de ocho folios cada uno (cuaterniones IX a XXXIII y XXXV a LII), más un fascículo de doce folios (senio XXXIV). Este último cuaderno, cuya extensión supera al resto y no es la habitual del manuscrito, ocupa justo los folios anteriores al único folio añadido en todo el códice, así el senio ocupa del folio 202 al 2I3, siendo el folio 2I4 la única adición claramente detectada de todo el manuscrito.

Este folio merece una descripción pormenorizada desde diferentes puntos de vista, y también desde el codicológico. En el recto y parte del vuelto del folio 2I4 aparece copiado un explicit del libro XXII, parte IV ${ }^{\mathrm{a}}$, lo que hizo coincidir el final del cuaderno con el final del capítulo, del libro y de la parte; pero en realidad ese explicit parece algo improvisado. Desde que parece que se pierde la escritura del copista habitual (f. 2I3v) con la marca añadida del final del libro y de la parte, hasta que retoma la escritura del texto el copista del folio 2I4, quien copia hasta finalizar, esta vez sí, el libro XXII y la parte IV7, hay una laguna en la que se localiza

6. Berganza y ArCe, Francisco de, Antigüedades de España, Madrid, 1721, parte I, pp. 177-178 y parte II, pp. 578-590.

7. Comparando la cantidad de texto que falta y que se conserva añadido al final del libro, con las ediciones modernas (M. Adriaen y J.P. Migne) la falta de texto del manuscrito equivaldría a un poco más de una columna. Ante esta falta de contenido y puesto que tres cuartas partes del f. $214 \mathrm{~V}$ un copista lo utiliza para realizar un dibujo, dos son las teorías posibles: o existió algún folio más en la encuadernación del manuscrito, hoy perdido; o bien el copista del 
fácilmente el contenido equivalente al final del libro XXII, capítulos 53 y 54. Se trata, por lo tanto, de una única interpolación que altera la conformación estructural del manuscrito. Además de los motivos paleográficos, mencionados en el apartado correspondiente, la confección de los cuadernos nos asegura que este folio se añadió con posterioridad a la copia del resto del códice, puesto que es necesario no contabilizar este folio para que encajen los siguientes cinco cuaterniones (del XXXV al XXXIX), llegando al cuaderno XL (f. 262v.), a partir del cual vuelve a aparecer la numeración original del copista habitual, hasta el cuaderno número LII, el último de los conservados.

Una vez establecida la falta de los cuadernos iniciales, parece razonable afirmar que si al códice le faltan al comienzo los siete primeros cuaterniones más seis folios del octavo, hemos perdido en total los primeros 62 folios del manuscrito. Del octavo cuaderno se nos han conservado los dos últimos folios. Así aparece, en la actualidad, numerado en las descripciones del manuscrito como folio Ir-v, puesto que es el primer folio que contiene escritura, el folio que en la numeración original correspondería con el folio $63 \mathrm{r}-\mathrm{v}^{8}$.

Por todo lo expuesto, es importante describir de forma minuciosa la disposición material del libro, puesto que presenta algunas peculiaridades que resulta conveniente aclarar en la medida de lo posible. La numeración de los cuadernos aparece por primera vez en el folio iov, según el cómputo actual, que como hemos advertido sólo considera la parte del texto conservada, y se corresponde con el cuaderno número 9 (q. IX). La marca del copista del quaternus VIII debería aparecer en el folio $2 \mathrm{v}$., pero la falta de la mitad inferior de los primeros folios restaurados, de los que sólo se conservan fragmentos, no permite comprobar datos de este tipo.

A partir de ahí, y siempre según la numeración actual, se mantiene de forma correcta la numeración hasta llegar al cuaderno XVIII, al que le falta un folio. Esta falta se detecta porque el cambio al cuaderno XIX, que debería haberse producido en el folio 9ov, en realidad aparece marcado en el folio $89 \mathrm{v}$. Ahora bien, no parece casual que el desajuste de la conformación material de códice se produzca en estos cuaterniones. En el folio 89v finaliza, sin falta textual, el libro XI y aparece el explicit expresado de forma muy breve, si lo comparamos con los que suelen aparecer en el resto del texto (Explicit liber undecimus). Después, aparece un hueco en blanco de unas diez líneas, para colocar a continuación el incipit del libro XIl ya en el folio gor.

A pesar de este pequeño desajuste el manuscrito, a partir del cuaderno XIX, sigue conformado por cuaterniones, hasta llegar al número XXXIV. Este es el

folio 214 prefirió dejar en blanco parte del pergamino con alguna finalidad concreta, aunque en realidad se utilizó con posterioridad para realizar un dibujo, más de acuerdo con el gusto del momento.

8. García Molinos, Elena, Florencio de Valeránica, caligráfo y notario del siglo X, en El reino de León en la Edad Media, León, Centro de Estudios e Investigación san Isidoro p. 334 escribe refiriéndose a este manuscrito: «carece de la mayor parte de sus ocho primeros cuaterniones y de varios folios de último cuaderno». Se menciona ya el problema que plantea este códice, aunque quizás de forma poco precisa. 
único senio que encontramos en el códice, compuesto por los doce folios que ocupan del f. 202r a 2I3v. Es en este último folio del senio donde encontramos el explicit improvisado y añadido del libro XXII, cuando en realidad, como ya hemos señalado, se produce una falta importante en el contenido del texto, que intenta paliar en parte el copista del folio $2 \mathrm{I} 4$.

La numeración de los cuadernos XXXV a XXXIX debería aparecer en los folios $222 \mathrm{~V}, 230 \mathrm{~V}, 238 \mathrm{v}, 246 \mathrm{~V}$ y $254 \mathrm{~V}$, pero no aparece visible ningún orden en los cuaterniones hasta el folio $262 \mathrm{v}$, donde se retoma con el número XL. Del resto del material escriptorio, es decir los cuadernos XLI a LIII, al que pertenece el último folio conservado, quedan restos más o menos legibles según los casos, de los cuadernos XLI (f. 27ov), XLII (f. 278v), XLIV (f. 294v), XLVI (f. 3Iov), XLVII (f. 3I8v), IL (f. 334v) y $\mathrm{L}$ (f. 342v), y no aparece ningún rastro de haber contenido un numeral en la parte inferior del intercolumnio en los cuadernos XLIII (f. 286v), XLV (f. 302v), XLVIII (f. 326v) ni tampoco en el LII (f. 358v).

Así, en lo que se refiere a la confección de los cuadernos, podríamos concluir que la división del material se realiza en cuaterniones de ocho folios, con la falta de un folio en el número XIX, regularidad que se mantiene hasta el cuaderno XXXIII; a continuación se incluye un senio, el único que aparece en todo el códice. La característica más reseñable del códice en cuanto a su estructura se refiere, se produce a partir del folio 2I3v, cuaderno XXXIV, cuando se intercala un folio añadido escrito por lo que hasta el momento se ha considerado una mano diferente, como veremos en el apartado paleográfico, unido al hecho de que no aparecen marcas de numeración, hasta el folio 262v. Desde ahí, al final del manuscrito conservado se sigue manteniendo la estructura de cuaterniones, de cuya numeración en muchos casos sólo quedan restos, seguramente por un problema no de confección sino de conservación, que no afecta al resto del texto.

De la parte final de los Moralia, tan solo se han conservado un par de folios de lo que conformaría el cuaderno LIIl y un folio suelto de un cuaderno posterior. Se trata, por tanto, de un códice de 360 folios conservados, con una falta segura al principio de 62 folios. Además, teniendo en cuenta que el final del texto tampoco está conservado, resulta difícil hacer un cálculo aproximado de qué extensión final debió de tener el códice.

Se ha establecido un análisis codicológico de los cuadernos tan pormenorizado, entre otros motivos, para poder determinar hasta qué punto B.Shailor establece una conclusión adecuada al separar e identificar la manos de dos copistas diferentes a partir de una clara división de los folios que conformas el códice.

En el análisis de este aspecto, no se puede tener en cuenta al escriba del folio 2I4, ya que no interfiere en la numeración de los cuadernos. Pero en el artículo mencionado Shailor propone una diferencia, para ella muy clara, de la forma que tienen los copistas I y II de numerar los cuadernos, y así afirma que mientras Gómez acompaña los numerales latinos a pie de página de varios puntos y un adorno, y nunca añade la letra «q», el copista II (quizás Aeximinus) utiliza los 
números para marcar los cuadernos sólo de forma esporádica, y cuando aparecen únicamente contienen el numeral romano, sin añadir ningún tipo de adorno. Esta afirmación supone que debería existir diferencia entre los cuadernos XXXV (f.222v), XXXVI (f.23ov) y XXXVII (f. 238v) que pertenecen al segundo escriba y el resto de los cuadernos numerados que corresponden al copista primero; pero las escasas diferencias en el modo de numerar no se distribuyen de este modo, como explicamos a continuación.

Desde el punto de vista gráfico los cuadernos se enmarcan con un ángulo alargado en su parte vertical, al que le siguen dos breves líneas o puntos en la parte superior del numeral latino, y cuya parte inferior se completa con dos líneas y un trazo vertical, realizado todo ello entra las columnas A y B en el margen inferior del folio. Ahora bien, a partir de este modelo se pueden observar algunas variantes que nada parecen tener que ver con la división de copistas propuesta por Shailor. La primera diferencia, que sí establece la intervención de una mano diferente, se da en el cuaderno XVI (f. 66v) donde se puede comprobar una morfología diferente tanto en el trazo de los números romanos como en su ornamentación. La segunda variante aparece en el cuaderno XXX (f. I77v), ya que es el único cuaderno que contiene la letra «q» después del número romano, como forma abreviada del término quaternus. Nada que ver, por tanto, con los cuadernos establecidos para el copista II.

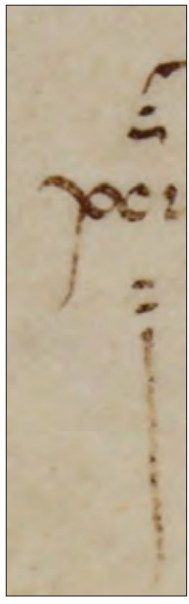

FIG. 1 F. 113V.

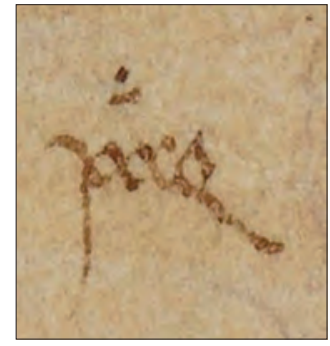

F. 177V.

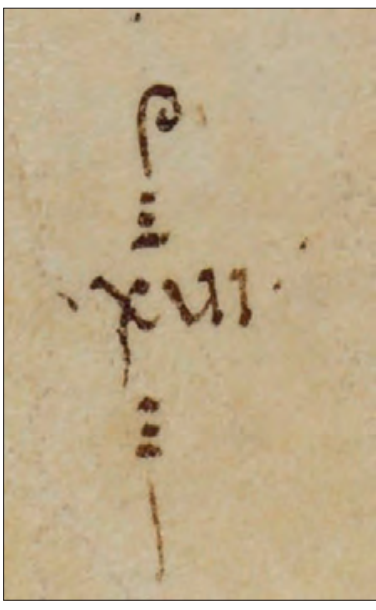

F. $66 \mathrm{~V}$.

(C) John Rylands Library, Manchester.

Como ya hemos señalado, en el resto de los cuadernos numerados tan sólo se pueden establecer dos constantes gráficas que no aportan datos sobre el número de copistas que intervienen en el texto. Así, desde el cuaderno XXXV hasta el LII, último conservado completo, en algunos casos tenemos restos, legibles o ilegibles, de la numeración original, y en otros casos el numeral y su adorno han 
desaparecido por completo; incluso, dentro de lo que parece una tendencia al desgaste del pergamino, de pronto el cuaderno XL se conserva completo y legible. Por otra parte, y en correspondencia con la descripción anterior, desde el cuaderno XXXV hasta el final del manuscrito, se desplaza el lugar donde se coloca la numeración, que pasa a realizarse debajo de la columna A en la parte izquierda del margen inferior, con la excepción de nuevo del cuaderno XL, que se mantiene centrada en el intercolumnio, como en los primeros 34 cuadernos.

Por lo tanto, el análisis gráfico de la numeración de los cuadernos nos lleva a pensar en la posible existencia de más de una mano en la confección del códice, pero desde luego no de forma tan secuencial y ordenada como se habría propuesto, sino más bien a través de intervenciones ocasionales de copistas simultáneos.

\section{EL MATERIAL ESCRIPTORIO}

El material escriptorio que conforma el códice tiene una doble numeración situada en la esquina superior derecha del recto de los folios, donde se puede observar cómo la actual tacha la anterior (por ejemplo, f. 357r). En cuanto a su estado de conservación, aunque podríamos describirlo como bueno de manera general, contiene algunas manchas de humedad en las esquinas superiores, diversas mutilaciones (ff. 6r y 244), agujeros (ff. 38, 46, 65, 74, 89, 97, 99, 244, 257, 279,...), agujeros cosidos (ff. 97, 279) y manchas de tinta roja en el folio I07v9.

El pergamino que se utiliza en la confección del códice es, por lo general, de buena calidad, pero se ha conservado en un estado muy irregular. Frente a los folios que se han mantenido tal y como se trabajaron en origen, tenemos otros muchos que se han podido salvar mediante una restauración moderna que ha conservado al menos sus dimensiones, y que ha evitado una desaparición completa del material.

En algunas partes del manuscrito se puede distinguir claramente entre la parte de la carne (interior) y la parte depilada (exterior) de la piel, hasta el punto de poder detectarse claramente el nacimiento e incluso la parte visible del pelo del animal, lo que da la sensación de no estar trabajado el pergamino con el máximo cuidado posible. En estos casos, se distingue también una diferencia de color muy clara entre las partes casi amarillas de las otras más blanquecinas. Junto a este grupo de folios en los que alternan tonalidades y texturas, hay grupos de folios que son casi blancos, y en los que apenas se puede ver alguna de las marcas habituales en el pergamino.

9. Después de analizar los agujeros del material en busca de una posible mutilación, resulta evidente que en realidad obedecen al momento de fabricación del pergamino. En ningún caso conllevan falta de texto, puesto que los escribas lo tienen en cuenta el realizar la escritura. 
Este tratamiento irregular del material no resulta tan extraño, si se tiene en cuenta que fueron varias las manos intervinientes en la copia del códice durante el tiempo en que se llevó a cabo su copia, lo que en el fondo significaba que posiblemente también fueron diferentes manos las que prepararon la piel hasta elaborar un pergamino apto para su uso como soporte escriturario. Como apunta José Antonio Fernández Flórez ${ }^{\text {Io }}$ los productos necesarios para confeccionar un códice es muy probable que no se comercializaran, por lo que serían los mismos monjes que escriben los encargados de cortar y tallar los cálamos o las plumas, de elaborar las diferentes tintas utilizadas y, por supuesto, de transformar la piel de un animal en una membrana pergamena.

Además, según la relación que establece M. C. Díaz y Díaz ${ }^{\mathrm{II}}$ entre el número de animales necesarios y la cantidad de material que se puede extraer, la piel de un animal daría lugar a medio metro cuadrado de material escriptorio, del cual se podrían obtener cuatro bifolios (8 folios o I6 páginas). Para obtener estos parámetros numéricos utiliza una medida estándar de aproximadamente 3IX2I centímetros cada folio. Si trasladamos estos datos a los más de 360 folios que tiene el manuscrito latino 83, haría falta reducir a pergamino la piel de, al menos, 45 animales que seguramente aumentaría su número sin consideramos que faltan folios, aunque no demasiados, y que las medidas de nuestro ejemplar oscila entre 4I,5-42 $\times$ 3I centímetros lo que aumenta necesariamente la cantidad de piel utilizada. En cuanto al pautado del material para su uso gráfico, se marca con punta seca los márgenes de doble línea a ambos lados de las dos columnas, con un intercolumnio y en cada columna se pautan las líneas de renglón. Esta disposición se mantiene a lo largo de todos los folios del códice.

\section{ANÁLISIS PALEOGRÁFICO}

Para realizar el estudio de los códices visigóticos conservados en la John Rylands Library, tanto desde el punto de vista codicológico como paleográfico es necesario partir, como ya se ha señalado, del excelente artículo realizado por la profesora Barbara A. Shailor sobre algunos de los textos adscritos al escriptorio del monasterio de San Pedro de Cardeña, copiados durante los siglos IX-X ${ }^{\mathrm{I} 2}$.

El manuscrito que aquí nos ocupa contiene la obra de San Gregoio Magno titulada Moralia in Iob y se conserva signaturizado con el número 83 dentro del

10. Ésta es una de las múltiples ideas interesantes que el profesor FERNÁNDEZ FLórEZ, José Antonio sugiere en su trabajo «Escribir, en León-Castilla, en la época medieval», publicado en Viajes y viajeros en la España medieval, Actas del V curso de Cultura Medieval celebrado en Aguilar de Campoo (Palencia) del 20 al 23 de septiembre de 1993, Fundación Santa María la Real-Ediciones Polifemo, Aguilar de Campoo- Madrid, 1997, pp. 145-175 (p. 157).

11. Díaz y Díaz, Manuel Cecilio, Libros y librerías en la Rioja Altomedieval, Logroño 1979, p. 17.

12. ShAILOR, Barbara, «The scriptorium of San Pedro de Cardeña», The Bulletin Jphn Rylands Library, Manchester 1979; en concreto para este trabajo las pp. 444-473. 
catálogo que M. R. James elaboró en I92 I para describir los manuscritos latinos que se encontraban custodiados en la John Rylands Library de Manchester ${ }^{13}$.

Ya en este catálogo aparecen datos referentes a la escritura del códice que se han perpetuado por investigadores posteriores, junto a otros datos de aceptación dudosa. En general se acepta que se trata de un códice copiado en el scriptorium de Cardeña, probablemente el primero o de los primeros, por un copista llamado Gómez que habría reconocido su autoría según un explicit que reproduce Berganza y recoge James:

Explicit foeliciter Liber Moralium Papae Gregorii, pars ultima: Deo gratias, Gomez Diaconus, peccator, hoc opus Era DCCCC.LII.VI. Kalend. Decembris, ob iussionem Domni Damiani Abbatis praescripsi ${ }^{14}$.

Dónde, además de la data cronológica, se nos informaría de que el texto fue acabado por el diácono Gómez en época del abad Damián, así como de que el códice contenía en su comienzo la carta que el obispo Tajo escribió a San Eugenio, arzobispo de Toledo.

Como ya se ha mencionado en el estudio codicológico faltan cuadernos del inicio y del final del códice, por lo que de estos datos tan sólo contamos con fuentes secundarias.

A partir de los datos que recoge James de la obra de Berganza, B. Shailor realiza un estudio de las características externas e internas del manuscrito, en el que analiza los diferentes aspectos del proceso de escritura de los only two are universally accepted as products of the Cardeña scriptorium dentro del grupo limitado de manuscritos visigóticos copiados entre los siglos VIII-XII ${ }^{15}$.

Para llevar a cabo el siguiente estudio paleográfico se han tomado como punto de partida las afirmaciones realizadas en el trabajo citado de la profesora Shailor. Dichas aportaciones se han cotejado en una nueva revisión del códice, a la luz de otras aportaciones más recientes de otros paleógrafos que también reflexionan en sus estudios sobre la escritura visigótica que se produce en la zona leonesa y castellana desde finales del siglo IX hasta principios del siglo $\mathrm{X}^{\mathrm{I}}$.

13. JAmES, Montague Rhodes; TAYLOR, Frank (ed.) A Descriptive Catalogue of the Latin Manuscripts in the John Rylands Library at Manchester, Manchester, University Press, I, 150-2; debe consultarse la reedición de este catálogo con introducción yl notas de Frank Taylor, München, Kraus Reprint, 1980, 27*-28*.

14. Berganza, Francisco de, Op. cit., vol. I, p. 177, James, Montague Rhodes; TAYlor, Frank (ed.), Op. cit., p. 152. Como ya se ha señalado, a la obra de Francisco de Berganza de deben algunos datos sobre este códice que no se pueden cotejar ya que no se conservan. Además de la fecha de finalización de copia de Gómez, 26 de noviembre de 914, sitúa la copia en época del abad Damián de Cardeña y advierte, asimismo, de que al principio de este manuscrito el autor incluyó la carta que el obispo Tejón escribió a san Eugenio, arzobispo de Toledo, al igual que en otras copias manuscritas de la misma obra.

15. B. Shailor en la cita se refiere a los Moralia (Ms. Lat. 83, J. R. L) y a la denominada Biblia de Cardeña (Archivo de la Catedral de Burgos).

16. Se ha consultado, y así aparece en el texto y en las notas correspondientes cuando es necesario, desde los trabajos clásicos sobre visigótica de A. Millares Carlo, A. Canellas López, S. García Larragueta, T. Marín Martínez, M. C. Díaz y Díaz, A. S. Mundó y Marcet o E. A. Lowe, hasta los más recientes de, J. Alturo Perucho, J. A. Fernández Florez, M. Herrero de la Fuente, J. M. Ruiz Asencio y Mª. J. Sanz Fuentes. 
El artículo del que partimos establece una serie de argumentos codicológicos señalados en el apartado anterior, a los que se unen los datos que aportan las descripciones paleográficas, que detallamos a continuación, para llegar a la siguiente afirmación: since there are, in fact three distinct hands in Lat. Ms. $83^{17}$.

Dejaremos al copista III para el final del análisis, ya que el verdadero problema gráfico del códice consiste en establecer si, como propone B. Shailor, el manuscrito fue copiado de forma mayoritaria por un escriba, Gómez, con la intervención de una segunda mano para el grupo establecido de folios (escriba II), o si, por el contrario, el análisis de los usos de los signos gráficos podría conducir hacia otras conclusiones diferentes.

Más numerosas son las diferencias entre copistas establecidas por B. Shailor dentro del ámbito paleográfico que del codicológico, por lo que en favor de la mayor claridad expositiva posible, resulta conveniente analizar los criterios paleográficos que utiliza para establecer cuál es la propuesta concreta que le lleva a dividir de forma tajante el texto entre dos copistas, uno de ellos a través dos intervenciones. Una vez cotejadas dichas afirmaciones con lo que se puede observar en el códice, se podrá establecer si los criterios utilizados son indiscutibles y cuáles son las características graficas que se pueden observar en la escritura visigótica del ms. Lat. 83 de la John Rylands Library.

Los criterios gráficos que se utilizan para la distinción de manos en el trabajo citado son principalmente tres: el uso de la abreviatura de la sílaba -bis, en el caso de Gómez con dos signos diferentes (la línea recta que corta el astil, o bien la cedilla bajo la letra «b»), frente al uso de la «b» cedillada como forma única en el copista II; la forma abreviada de las palabras id est también sería diferente, así el usus scribendi de Gómez se decantaría por las formas idt o idst como componente alfabético con el signo general sobrepuesto, mientras que el otro copista cambiaría en parte dicho componente alfabético al utilizar en sus folios las formas ids o idst. En tercer y último lugar, detecta un tipo de «i-longa» en Gómez

17. Shallor, Barbara, Op. cit., p. 448. En la misma página se aportan los datos referidos a las diferentes medidas de la caja de escritura que utilizan cada uno de los escribas del códice, donde distribuye los copistas intervinientes en la copia del siguiente modo:

Escriba I (Gómez), ff. 1-213v (G1) y 242v-36l $\left(\mathrm{G}^{2}\right)$, caja de escritura $316 \times 225 \mathrm{~mm} .417 \times 302 \mathrm{~mm}$..

Escriba II («in a hand less skilled than that of Gómez»), ff. $215 \mathrm{r}-242$ r, caja de escritura $320 \times 235$ mm

Escriba III («which was apparently inserted later»), f. 214, caja de escritura $316 \times 225$ mm.

Sobre lo ajustadas que pueden ser las mediciones realizadas en un códice de este tipo tan sólo señalar que, por una parte Shailor da como media del folio $417 \times 302$ mm., James en su Catálogo, de dónde lo toma la biblioteca custodia en su descripción, $420 \times 300$ mm., y yo misma lo he medido recientemente en $415-420 \times 310 \mathrm{~mm}$. y doy por cierto que los tres hemos visto el manuscrito. Por otra parte, la caja de escritura de los escribas I y III coinciden exactamente según establece Shailor $(316 \times 225 \mathrm{~mm}$.) y se trata claramente, según ella, de dos copistas distintos. Si trasladamos la división del manuscrito por copistas que propone Shailor al texto de los Moralia, el copista I escribe desde el inicio hasta casi el final del Libro XXII y desde el Libro XXV, 34,27 XII.29 hasta el final del códice. El copista II escribe desde el libro XXIII, parte quinta hasta el libro XXV, 34,27 XII.28. El copista III escribe un folio (214) que corresponde a la parte final copiada del libro XXII; aunque con respecto al contenido de la obra de san Gregorio falte parte del texto, aun después de incluir la adenda. Por lo tanto, la intervención de este escriba supondría una transición textual entre los copistas I y II, quizás este hecho lleve a pensar a Shailor en un posible cambio de mano, además de los argumentos explicados en su artículo. 
(y también en el escriba III, a pesar de que lo menos discutible es que se trata de un añadido posterior) que se realiza con una morfología diferente por parte del escriba II, la diferencia se localiza en la parte superior de la letra colocada encima de la caja de renglón, así los copistas I y Ill realizan la parte superior de la letra con forma de horquilla que se abre hacia la izquierda, una parte, y hacia la derecha la otra, frente al escriba Il que realiza dicha horquilla con un leve giro final hacia la izquierda en ambas partes.

Establecidos los argumentos se hace necesario comparar dichas afirmaciones con una muestra lo más amplia posible de lo que se puede observar en el manuscrito. Por lo que respecta al uso de la forma abreviada - bis efectivamente a lo largo de todo el texto se pueden encontrar las dos formas descritas, pero en realidad la forma que más aparece no es ninguna de las abreviadas sino la forma explícita, tanto en la parte adscrita a un copista como al otro y de forma no significativa entre unos folios u otros, ya que las tres formas posibles (las dos abreviadas y la explícita) se distribuyen por todo el texto de forma aleatoria ${ }^{18}$.

Otra de las diferencias se refiere al gusto de los escribas por adoptar un componente semántico $\mathrm{u}$ otro en la forma abreviada latina id est. La forma idst aparece utilizada por ambos copistas, como ya señalara Shailor, pero no es real establecer una diferencia de uso entre las formas idt/ids, ya que son numerosos los casos en que Gómez utiliza ids (253 v, 254r, 268v, 290r, 302r) del mismo modo que en el escriba Il encontramos casos del uso de la forma idt (223v, 227r, 23IV, 228r, 235r), teniendo además en cuenta que, por ejemplo, en el folio 302, adjudicado a Gómez nos encontramos con las dos formas, y en el folio 227 ocurre lo mismo, adscrito en este caso al copista Il. También en este caso, como en el anterior, en ocasiones los copistas optan por no utilizar la forma abreviada (f. I04r), pero son mucho menos frecuentes.

Por último, se había señalado el uso de dos morfologías diferentes según los escribas en la denominada «i-longa». Desde el punto de vista gráfico, se trata de un $i$ alta que en ocasiones se atiene a la caja del reglón en su parte inferior, y en otras desarrolla un caído, cuya parte más significativa se encuentra en su astil que termina en forma de horquilla abierta hacia ambos lados (así, Gómez y el escriba III) o girada hacia la izquierda (el escriba II). Creo que resulta un dato suficientemente esclarecedor el hecho gráfico de que en el folio 2I5v, por ejemplo, encontramos una morfología en la columna A y la otra posible en la columna B. Además, son muchas las ocasiones en que tanto en la primera parte que copia Gómez como en su segundo grupo de folios utiliza, sin una distinción aparente, ambas formas ${ }^{\mathrm{I}}$.

18. Las palabras que de forma repetitiva aparecen abreviadas en el códice son nobis y uerbis, y de ambas tenemos ejemplos en su uso explícito (110v y 219v), con el signo general unido al astil (168v y 138v) o el signo cedillado (205r), en ambos copistas.

19. El uso de esta morfología de $i$ aparece con mucha frecuencia en las palabras: ait, Moises, Esaias, hipocritae o misterium, así como en otras palabras que se producen de forma más aislada. En todos los casos citados existen testimonios del uso de ambas morfologías, a veces incluso en el mismo folio (véase hipocritae, f. 315r). Desde el punto 
La realidad gráfica es tozuda y apunta en todos los casos analizados en el mismo sentido. La división establecida por B. Shailor no se puede mantener tampoco desde el ámbito paleográfico, como ya vimos en el codicológico, y el análisis que ella misma propone, seguramente sin posibilidad de realizar consultas constantes al manuscrito, da como resultado el uso de unas formas gráficas, por parte de los copistas, de la escritura visigótica redonda que son las habituales en un texto con sus características copiado a principios del siglo X en la zona burgalesa.

Ahora bien, intentaré explicar a través del análisis gráfico de dicha escritura, que sí se pueden detectar dos manos diferentes en el texto (además del escriba III y de numerosas anotaciones coetáneas y posteriores en los márgenes del manuscrito), pero que de ningún modo creo que puedan adscribirse a folios agrupados, ni siquiera a folios completos, sino más bien a intervenciones que se pueden detectar en diferentes momentos puntuales de copia a lo largo de todo el texto.

De forma general, se podría describir la escritura del manuscrito latino 83 como una visigótica redonda, de aspecto todavía algo pesado, sobre todo en astiles, con las letras realizadas en su mayor parte de forma aislada (aunque se puede constatar la existencia tanto de nexos como de ligados) y una separación de palabras elaborada todavía de forma irregular.

\subsection{LETRAS AISLADAS}

No resultan muy relevantes los datos que aportan el análisis de las letras $m, n$ y $h$, ni tampoco el grado de cerramiento del ojo de la letra $b$. En el primer grupo se observa que todas las letras que contienen un trazo vertical (bien como astil o bien dentro de la caja de renglón) que acaba su trazado en la línea de renglón, finaliza dicho trazo con un alargamiento hacia la derecha (así, se unen a este grupo la $i$, alta y corta, la $u$, la $l$, y la $a$ (esta última aún más alargada por motivos morfológicos). En el caso del ojo de la letra $b$, aparece con una forma cerrada o prácticamente cerrada a lo largo de todo el texto ${ }^{20}$. Es también destacable paleográficamente el uso que se realiza de las morfologías cursivas de la letra $a$, como una épsilon inclinada hacia la izquierda, y de la letra $u$, con una finalización en

\footnotetext{
de vista gráfico, además de las dos formas descritas se localizan casos de este tipo de $i$ con un punto sobrepuesto ( $f$ 104v) o con un caído que en ocasiones forma parte del ductus incial de la letra (ff. $268 \mathrm{r}$ con horquilla a izquierda y $273 \mathrm{r}$ con horquilla a izquierda y a derecha) y en otros casos aparece añadido de forma postiza (f. 112r).

20. Como explica el profesor CANELLAS LóPEZ, Ángel, «Algunos membra disiecta en visigótica sentada pirenáica, con fragmentos de las Collationes Cassiani, del siglo X» Actas del VIII Coloquio del comité Internacional de Paleografía latina, Joyas Bibliográfica, Madrid, 1990, pp. 39-50, es propio de los códices de comienzos del siglo X el empleo del ojo cerrado de la letra $b$. En cuanto a los diferentes tratamientos del último trazo de las letras $m$ y $n$ no son significativos para precisiones cronológicas. No obstante, a pesar de que, según Canellas, la verticalidad del trazo final de dichas letras conduce a la primera mitad del siglo X y el alargamiento de la $h$ hace pensar en el siglo XI, quizás por diferencias de tipo geográfico, en nuestro códice, bien al contrario, se producen estos casos con las mismas características gráficas en todos ellos, un claro alargamiento hacia la derecha.
} 
caído recto al modo de la mayúscula. En muchos casos van colocadas al final de línea o de palabra, aunque no siempre y se observa más frecuencia de su uso en la segunda mitad del manuscrito que en la parte inicial ${ }^{21}$.

En cuanto a la sílaba -ti no se produce una distinción gráfica entre los usos asibilados y los no asibilados, pero existen casos en los que la $i$ corta, trazada en inicio, cuando se corresponde con el sonido suave se convierte en una letra con un caído postizo ${ }^{22}$; de hecho en las anotaciones marginales y en los interlineados escritos en visigótica redonda, aunque con algún rasgo más de cursividad que la del cuerpo del manuscrito, ya sí es corriente el uso de la $i$ larga para escribir el sonido asibilado en el grupo - $t i$. El alargamiento posterior de dicha letra parece producirse de forma arbitraria, ya que en el mismo folio se dan casos en los que se moderniza la letra mediante un caído, y otros casos que, representando el mismo fenómeno lingüístico carecen de marca gráfica ${ }^{23}$.

La morfología de las letras mayúsculas es la habitual en la escritura visigótica de este momento. En este aspecto tampoco se puede establecer una división de manos por grupos de folios, según reconoce B. Shailor, ya que la única diferencia que se puede establecer es de tipo cuantitativo y está inducida por el elevado número de folios adscritos al copista $\mathrm{I}$, frente a los escasos folios copiados por el escriba número II.

\subsection{NEXOS Y LIGADOS}

La forma anexada más habitual es la que forma la letra $t$, en su morfología de beta invertida, seguida de las letras i larga, $r$ o $s$. También es frecuente el nexo -at (sobre todo usado en las flexiones verbales, así f. 357v dicebat) y también en posición final de palabra la sílaba -it completando el astil de la letra $i$ alta con una línea horizontal con diferentes grados de ondulación en la parte superior.

21. En el caso de la a cursiva se puede localizar en al menos cincuenta ocasiones en el texto, más de la mitad se sitúan como final absoluto de línea o dentro de la última palabra. Del mismo modo, su uso es más frecuente a partir de folio 274 que en los folios anteriores. CAMINO MARTíneZ, Carmen del, «Los orígenes de la escritura visigótica: ¿otras posibilidades para sus estudio?», Actas del VIII Coloquio del Comité Internacional de Paleografía latina, Joyas Bibliográficas, Madrid, 1990 pp. 29-37, al estudiar los orígenes de la escritura visigótica, se plantea si un mismo copista conocía los registros redondo y cursivo, y si los usaba de forma indistinta; en el siglo X parece que la inclusión del modelo de algunas morfologías cursivas dentro del alfabeto de la redonda no debía ser tan inusual. De manera paralela la letra «u» con un claro caído con final de su segundo trazo se utiliza para las terminaciones en -tum y -tur, en este caso su uso se reparte por igual a lo largo de todo el texto, así hay ejemplos desde el folio $7 \mathrm{r}$ (nesciatur) hasta el folio $309 \mathrm{r}$ (sequntur).

22. Los trazos postizos que alargan la letra $i$ cuando se trata del fenómeno «t+yod» aparecen en diferentes partes del texto, como ejemplo puede verse en el $\mathrm{f} .129 \mathrm{v}^{\mathrm{b}}$ donde encontramos los casos de delectjonibus, penitentjam y actjone.

23. Los casos que cita LowE, Elias Alvery, Palaeographical papers 1907-1965, Oxford, 1972, p.51, «actjo» (f.58r) y «actjonibus» (f.292r) se encuentran realizadas en añadidos interlineados por un corrector contemporáneo, de hecho en las correcciones o anotaciones realizadas en escritura visigótica lo corriente es encontrar la distinción gráfica realizada. Sí aparece dicho alargamiento postizo dentro del texto de las columnas en otros casos, así en el f. $129 \mathrm{v}$ «delectatjonibus». Como ejemplo del uso aleatorio de este fenómeno gráfico véase el f. 284v, donde encontramos «exercitatjone», «deliberatjone», «temtatjonis» o «\stul/titjam», y también puede leerse «cogitationem», «essentia», «cogitationibus» 0 «inmunditie». 
Del mismo modo que en el caso anterior también se utiliza como desinencia en la flexión verbal (f. 9r diligit, f. 5Iv dicit o f. 2I9v conmicit).

En cuanto a los ligados, se realizan siempre por el alargamiento del trazo final de las letras $r, m, n, \mathrm{y} h$ hacia la siguiente grafía, en ocasiones resulta muy artificial debido a un prolongamiento excesivo (f. 34Iv. ferunt). Otra modalidad de este mismo ligado consiste en prolongar la letra de forma vertical subiendo el trazo por encima de la caja de renglón, hasta formar casi una especie de astil (f. 225v. firmitate). En ocasiones se realiza también la unión entre las letras $s$ y $t$.

\subsection{SISTEMAS ABREVIATIVOS}

Se utilizan los sistemas abreviativos con corrección. El punto y la línea sobrepuestos y el corte en los astiles, se utiliza como la morfología del signo con valor general, se usa el trazo con forma de doble curva sobrepuesto para los finales en -us y -ue (para la sílaba que abreviada) y se utiliza el alargamiento de $n, m, r$ y $t$ de beta invertida cortado por el signo general para las terminaciones en -um. De forma paralela también aparecen las formas -ur, -us y -um con una pequeña $v$ colocada encima de la palabra, pero en estos casos la palabra aparece de forma explícita, sin ninguna falta semántica. La abreviatura de la sílaba -bis aparece con una doble morfología de astil cortado y cedillada. La sílaba per se abrevia mediante el corte con el signo abreviativo, bien de forma rectilínea o curvilínea, del caído de la letra $\left\langle\mathrm{p} »^{24}\right.$.

\subsection{SIGNOS DE PUNTUACIÓN}

Al tratarse de un códice de una considerable extensión, en el manuscrito se pueden encontrar muchos de los signos gráficos posibles que dotan al texto de un sentido completo.

Para las pausas, tanto de respiración como de redacción, utiliza diferentes formas gráficas. Así, para las pausas leves, equivalentes a nuestra coma actual, utiliza el punto en el centro de la caja del renglón, resulta muy significativo como utiliza este signo cuando tiene que realizar enumeraciones (f. 45r, quem ab eius ueniam•spes $\bullet$ fides et karitas). En el caso de las pausas intermedias o fuertes utiliza la coma-punto, el punto-coma, este último tanto con inclinación a izquierda como a derecha, los dos puntos en sentido vertical o inclinado, y los tres puntos en forma de triángulo.

24. Por lo que se refiere el componente semántico de las palabras frecuentemente abreviadas no revela ninguna diferencia de uso durante el proceso de copia del texto así, por ejemplo, misericordiam (mrscdam), gloria (gla), populum (pplm) o autem (aum). 
En cuanto a las marcas gráficas que denotan admiración e interrogación son también las habituales en el sistema gráfico dela escritura visigótica. Se utiliza el acento circunflejo normal o invertido según se trate de frases interrogativas generales o parciales. Las frases que requieren un signo exclamativo conllevan un círculo con un punto en el centro colocado generalmente al principio de la frase, aunque la situación de dicho signo al final de algunas exclamaciones hace pensar en toda la morfología como un signo con valor propio y no sólo como una forma mezcla de valor alfabético y simbólico.

\section{ORNAMENTACIÓN}

Se trata de otro de los aspectos del códice en los que B. Shailor establece una diferencia entre la parte del texto realizada por Gómez y los folios adjudicados a un segundo copista ${ }^{25}$. Según expone en su trabajo las letras mayúsculas adornadas por Gómez se realizan con hábil factura, frente a las que realiza el segundo copista, que son más pequeñas y de menor dificultad en su ornamentación.

Tampoco en este sentido está claro que se pueda defender la distribución establecida de manos intervinientes, ya que no existen diferencias cualitativas entre el estilo ni el tamaño de la iluminación que se utiliza en los folios 2I5r a 242r con la del resto del manuscrito.

El uso del dibujo y del color a lo largo del texto es variado y constante. En las numerosas letras iniciales miniadas se pueden detectar diferentes formas de combinar los elementos con los que va trabajando el copista ${ }^{26}$, así algunas contienen los cuatro colores usados en el texto, negro, rojo, verde y amarillo ${ }^{27}$, o la mezcla de

25. Según Barbara Shailor las diferencias en la iluminación ya las detectó M. R. James, pero en realidad la única frase que hace referencia a este aspecto en su catálogo es la siguiente «The book contains a multitude of small decorative initial, mostly the work of one hand» (JAMES, Montague Rhodes; TAYLOR, Frank (ed.), Op. cit vol. I, p. 152), donde no habla exactamente de dos manos, ni mucho menos las identifica.

26. Tras la comparación de las iniciales miniadas del texto con las de otros códices de la época mediante las reproducciones y la descripción que realizan AvRIL, François., ANIEL, Jean-Pierre., Mentre, Mireille, SAULnier, Alix y Zatuska, Yolanta., Manuscrits enluminés de la Péninsule lbérique, Paris, Bibliothéque Nationale, 1982, en general, se pueden observar algunos elementos similares (se observa alguna similitud con el ms. lat. 2855 que hace referencia más a la morfología de las iniciales que a su forma de adornarlas), pero en ningún caso las similitudes permiten adscribir al códice de la John Rylands Library a ninguno de los monasterios que aparecen recogidos en el estudio para principios del siglo X, lo que quizás apunta a los diferentes orígenes de los códices.

27. Aunque puede resultar extraña la falta del color azul en la paleta básica de los copistas de este códice, según explica Patoureau, Michel: «Durante mucho tiempo, en los libros miniados, el azul es escaso y muy oscuro, es un color secundario o periférico, ya que no tiene una simbología propia y no participa, o casi no participa, en la significación de las obras de arte y las imágenes. Por otra parte, hasta el siglo X u XI son numerosas las iluminaciones de las que está totalmente ausente, sobre todo, en las islas británicas y en la península ibérica», Azul. Historia de un color, BarcelonaBuenos Aires, Paidos, 2010, p. 46. En el mismo sentido apunta el estudio de los manuscritos iluminados visigóticos que se conservan en la Biblioteca Nacional de Francia ya mencionado, ya que de los volúmenes de los siglos IX y X que se recogen, tan sólo cuatro como máximo de los 18 conservados mantienen algún resto del color azul. Sobre el uso del color en esta época véase también DufEIL, Michel-Marie, «Du couchant des Orients à l'Azur de l'Europe» en Les couleurs au Moyen Âge, Aix-en-Provence, 1988, Presses universitaires de Provence, pp. 87-108; y GousSET, MarieThérèse et STIRNEMANN, Patricia, «Indications de couleur dans les manuscrits médiévaux» en Pigments and colorants de 
cualquiera de ellos en combinaciones de dos, tres o cuatro elementos, utilizando incluso la monocromía. Las letras se pueden encontrar con perfiles marcados combinando los colores, o sin perfil alguno. En cuanto a las morfologías de estas formas gráficas van desde las más sencillas de módulo pequeño monocromas que reproducen la forma esencial de la letra, hasta las de mayor ornamentación con motivos zoomórficos y antropomórficos, pasando por algunas que incluyen elementales motivos vegetales ${ }^{28}$.

Así pues, por lo que se refiere al grupo de iniciales miniadas, encontramos una regularidad absoluta durante la copia del códice tanto en el uso del color, de las formas (en su mayor parte simples dibujos geométricos), e incluso en la distribución de diferentes tamaños; ya que tampoco en sus medidas se puede establecer una diferencia entre dos copistas, según los cuadernos que establece B. Shailor. En un escaso margen de un centímetro de diferencia se pueden localizar las mismas iniciales con dibujos muy similares en los folios de los supuestos dos copistas, del mismo modo que tampoco se ha podido localizar ninguna característica que pueda hacer distinguir desde el punto de vista de la ornamentación unos folios de otros.

En el mismo sentido apunta el análisis de las partes del texto que contienen de forma continuada algún tipo de adorno tanto de tipo puramente gráfico, como artístico, me refiero a los íncipit y a los explicit. Los folios no atribuidos a Gómez equivalen en el texto gregoriano a los capítulos 32, 33 y 34 de los libros, 23, 24 y 25 de la parte quinta, dentro de los cuales se copian tres comienzos de capítulo y dos finales, ya que el folio $2 \mathrm{I} 5 \mathrm{r}$ comienza con un íncipit, quedándose su explicit anterior en los folios atribuidos a un tercer copista que realizan tan solo el folio 2I4. Pues bien, en estas partes tan marcadas del códice no sólo pueden encontrarse los mismos juegos de alternancias de colores en líneas y palabras, así como el gusto por la monocromía en los explicit frente a la policromía más usada en el incipit, sino que también se da el caso de que la ornamentación del explicit-incipit del folio $236 \mathrm{r}$ (atribuido al copista II) es exactamente igual al que utilizara Gómez en el f. 203v, así en ambos casos el uso del color se distribuyen en una alternancia de

\footnotetext{
I'Antiquité et du Moyen Âge, Colloque international du CNRS, Editions du Centro National de la Recherche Scientifique, Paris, 1990, pp. 189-198..

28. Dentro de los motivos zoomórficos que constituyen algunas iniciales miniadas la mayoría reproducen pájaros, pavos y peces, tanto de forma individualizada, como uniendo en la misma letra pájaros y peces, así con estos dibujos realizas las letras $A$ (con diferentes morfologías), H, M, N, P, Q, S, T y U. En otras ocasiones se utiliza un caballo como base gráfica de la letra S. Por lo que se refiere a las letras que incluyen motivos antropomórficos se ha localizado en diez ocasiones, que se distribuyen en el uso de una $\mathrm{M}$, dos veces la letra I, tres casos de la grafía $\mathrm{P}$, siendo la letra $\mathrm{Q}$ la más utilizada, en cuatro ocasiones, en todos los casos según los requisitos de la morfología esencial de la letra, aparece la figura tumbada o de pie, y con diferentes adminículos que completan el dibujo como es el caso de unas alas para letra M uncial o un bastón para la letra P. Es reseñable que todos los casos de iniciales con ornamentación antropomórfica se contienen al final del texto conservado, de hecho se encuentran entre los folios $270 \mathrm{r}$ a $328 \mathrm{r}$.

En cuanto a los casos en los que aparecen motivos vegetales, la hiedra es el único elemento que se utiliza, quizás por el simbolismo que había adquirido en el arte cristiano durante la Alta Edad Media (véase, QUIÑONES CosTA, Ana María, La decoración vegetal en el Arte Español de la Alta Edad Media: su simbolismo, Madrid, UCM (tesis doctoral), 1992, tomos I y II, pp. 179-182.
} 
verde-rojo en cada una de las palabras que componen dichos títulos, manteniendo el mismo orden del uso del color en las palabras, incluso en las que se realizan con trazo bicolor perfilando la morfología esencial de cada letra.

Además del uso del color y del doble trazo en algunas de las letras mayúsculas que conforman los tituli de la obra, el único elemento que se encuentra como adorno es una hoja de hiedra al final de la última línea, muy similar si no igual que la que aparece en los epígrafes medievales. Si aplicamos el uso de este elemento como posible ayuda para el establecimiento de manos nos encontramos con la misma hoja de hiedra en el íncipit del folio 26or, copiado por Gómez, y en el íncipit del folio 2I5r supuestamente no copiado por él. Se observa también el gusto por el adorno en la forma gráfica de algunos signos abreviativos en los que se sustituye la línea recta por formas dentadas que se realizan en color verde y se perfila en rojo.

El análisis, por tanto, de la ornamentación del códice parece abundar en el mismo sentido que los apartados ya estudiados en cuanto al proceso de escritura del manuscrito, indicando que una distribución de manos por grupos de folios, como la propuesta, no se puede justificar tampoco en el ámbito de la decoración del códice.

\section{CUESTIONES LINGÜÍSTICAS}

Sin pretender realizar un análisis exhaustivo de las características que presenta la ortografía del texto, sí parecen reseñables algunos fenómenos que desde este punto de vista describen un uso concreto dentro de las posibilidades que ofrece el latín medieval del siglo X.

Así, es característico de los copistas de este códice utilizar la forma gráfica $k$ en la palabra karitas y sus formas derivadas, en lugar de la letra c-, y aunque está muy clara su preferencia en este sentido, se pueden encontrar alternando ambas formas no sólo en el mismo folio, sino en la misma línea (f. 47v). El uso del sonido /k/ representado por esta letra se observa en algún término más, como es el caso de kathedram (f.I74r).

El grupo ti, como se ha explicado en el análisis paleográfico, no aparece marcado de forma gráfica a través del uso de la $j$, pero son varios los ejemplos en los que nos encontramos que la letra inicial del grupo ha evolucionado a la letra $c$ en un caso claro de acercamiento a la oralidad. Así escriben condicionis o condicione en los folios 23IV, 235v, 236r, o 360v, por ejemplo, pero quizás es la conciencia de que la escritura permanece lo que les lleva escribir en el mismo folio y columna 
condicione pero también actione, sin ni siquiera marcar la asibilación en los signos gráficos ${ }^{29}$.

Estos procesos en los que los copistas demuestran dudar entre las formas nuevas cercanas a la oralidad y las tradicionales que han aprendido en la escritura, dan cuenta del cambio lingüístico que cuando menos comienza a fraguarse en estos momentos, así se refleja también en la sustitución del grupo culto $p h$ por $f$, pero se puede leer prophete en el folio $225 \mathrm{v}$; en el hecho de que junto al uso habitual de la forma latina scriptum (f. 223v) se detecte la forma antietimológica scribtum (f. I26v) en algunas ocasiones; o en el uso de palabras con pérdida de la vocal $i$ inicial de apoyo, como son los casos de los términos storia, srhlitico, srhl (ff. 248r, 254r).

\section{ANOTACIONES MARGINALES, COMENTARIOS INTERCALADOS Y PRUEBAS DE PLUMA}

Dentro de las frecuentes apariciones en los márgenes de diferentes tipos de marcas gráficas, tanto simbólicas como verbales, merecen un análisis más detallado las correcciones que consisten en añadir al texto las partes, que por error, fueron omitidas en el proceso inicial de copia. Este tipo de anotaciones dan cuenta, por un parte, de cuál era el uso gráfico habitual para marcar este tipo de ausencias en los códices visigóticos, y por otra, nos permite asegurar que este texto se copió de otro ejemplar anterior, que por su temprana fecha en los inicios de la fundación de Cardeña, es más probable que procediera de un préstamo de otro monasterio, que del fondo del propio monasterio.

Puesto que desconocemos qué códice sirvió de modelo para la copia del manuscrito latino 83 de la John Rylands Library ${ }^{30}$ los fragmentos que faltan con respecto

29. Sobre la evolución de la forma asibilada ti en la evolución del latín al romance han expuesto su opinión los lingüistas más importantes, así MENÉNDEZ PIDAL, Ramón, Manual de gramática histórica española, Madrid, EspasaCalpe, 199923, p. 94, escribe «Los grupos TY y CY asibilaban sin oclusiva desde el siglo II [...] para asimilarse [...] a la yod, haciéndose palatales. Sin embargo, la sibilante TY era diversa de CY, aunque bastante parecida para prestarse a continuas confusiones que se cometen en los siglos III y IV: mandatium, justicia, etc...». En la Historia de la lengua española, coordinada por Rafael Cano, Madrid, Ariel, 2013², en el capítulo 6 elaborado por el profesor GIL, Juan, con el título «El latín tardío y medieval (siglos VIII-XIII), pp. 149-180, cita a san Isidoro «Según San Isidoro (Etym. I, 27, 28) al pronunciar ti se produce un sonido diferente y parecido a la z griega, aunque se deba respetar la grafía tradicional: cum 'iustitia' sonum z litterae exprimat, tamen, quia latinum est, per T scribendum est», p. 160; y el profesor BusTos Tovar, José Jesús de, en el capítulo 10, «la escisión latín-romance. El nacimiento de las lenguas romances: el Castellano», en la p. 268 al hablar de la época de orígenes (ss. VIII-IX) explica que «existieron dos etapas arcaicas en el proceso de escisión latino-romance. La primera corresponde al periodo visigótico [...] la lengua escrita se mantenía básicamente uniforme (el modelo podría ser el latín isidoriano) [...] No puede pensarse que hubiera una interrupción en la tradición hasta finales del XI [...] En esta época el romance quedaba reducido al uso hablado».

30. En cuanto a la existencia de posibles códices anteriores a este, como ya anotara Fernández Flórez, José Antonio, «Escribir, en León-Castilla, en la época medieval», en Viajes y viajeros en la España medieval, Actas del V Curso de Cultura Medieval celebrado en Aguilar de Campoo (Palencia), Polifemo, Aguilar de Campoo-Madrid, 1997, pp.145175, en la p. 163, n.68 «La obra de san Gregorio Magno [Moralia in lob] tuvo una gran difusión en España, y el número de códices o fragmentos conservados se han seguido incrementando en los últimos tiempos. En fecha relativamente reciente J. M. Ruiz Asencio («Documentos y códices altomedievales de San Román de Entrepeñas» en Actas del I congreso de Historia de Palencia, II: Fuentes documentales y Edad Media, Palencia, 1987, pp. 9-50) ha dado a conocer un 
a la obra gregoriana podrían deberse a su falta ya en el texto inicial. Pero dejando a un lado el problema textual, se pueden detectar un número importante de lagunas que en realidad se deben a lo que la crítica textual denomina errores de copia por homoioteleutón, que tan útiles son para determinar los procesos de copia de los códices de una misma obra, con la finalidad de poder establecer un stemma definitivo de su tradición textual. Nuestro interés, en este caso, no va enfocado a la posible filiación de códices, ya que sólo analizamos un ejemplar dentro de la tradición de los Moralia in Iob de san Gregorio, sino que se remite al análisis de estos errores de copia desde el punto de vista paleográfico y los datos que ofrecen para el estudio de los usos gráficos de los copistas en el siglo X castellano ${ }^{31}$.

Como ya apuntara E. A. Lowe ${ }^{32}$ los signos gráficos que se utilizan para marcar la omisión del texto en los códices visigóticos son las formas abreviadas $d h$ (deorsum hic) que se corresponde con un Svr o SR (super) colocados antes o después junto a la inserción, en la parte izquierda del margen inferior. En los folios que se conservan de nuestro manuscrito este proceso se lleva a cabo en al menos 84 ocasiones con suficiente cantidad de texto como para establecer que dichas anotaciones se llevan a cabo por dos manos diferentes, o incluso alguna más. Podría tratarse de lectores y/o correctores del texto que al detectar las faltas de contenido deciden añadirlo para completar la obra, bien copiando del mismo ejemplar que copiaran los copistas iniciales o bien de otro. En todos los casos realizan escritura visigótica sentada, diferenciadas claramente entre sí por la realización de astiles con distintas terminaciones, y que hacen pensar en una cronología algo posterior al momento de copia del códice, ya que muestran en todos los casos la opción tj como forma asibilada.

Existen, además, casos en los que la falta de texto se marca a través de un signo de carácter más simbólico que alfabético. La morfología de dichos signos es variada, así aparecen tres puntos en forma de triángulo en ocasiones con una línea ondulada en el centro o en forma invertida, e incluso se añade texto sin ningún tipo de llamada de atención escribiendo la falta directamente en la columna o en los márgenes laterales. Frente a la escritura redonda que encontramos en los primeros fragmentos añadidos marcados a lo que he aludido, con las formas $d h$-SR, las formas cursivas están presentes en muchas de las palabras y líneas añadidas mediante estos procedimientos más directos y sencillos. En estos casos también

\footnotetext{
interesante folio, escrito en tres columnas, «en escritura visigótica andaluza muy primitiva siglos VIII-IX conteniendo unos Moralia in lob de San Gregorio Magno» (p. 10)».

31. Los errores de copia por homoioteleutón proceden de saltar visualmente de una palabra a otra igual cercana dentro del proceso de copia, omitiendo así la frase intermedia y se producen con cierta frecuencia en el texto. Se han localizado por ejemplo en los folios 165v, 213v, 227v, 236, 254r o 274v, marcados gráficamente con diferentes llamadas de atención.

32. El trabajo de LoWE, Elias Avery sobre los signos de omisión en los manuscritos visigóticos está recogido en Paleographical papers 1907-1965, Oxford, 1972, vol. II, p.367. En la descripción del manuscrito que aquí nos ocupa, con respecto a este tema solo hace referencia en la página 371 a los casos de los folios $29 \mathrm{~V}$ y $274 \mathrm{v}$.
} 
utilizan la distinción gráfica en las formas asibiladas y podría llevar a pensar, incluso, en una tercera revisión con aportaciones que contienen menor cantidad de texto.

Junto a las marcas gráficas mencionadas aparecen otro grupo de signos como una serie de puntos verticales al comienzo de la línea, cruces, cristus, y líneas verticales con diferente extensión finalizadas o atravesadas por pequeños trazos ondulados, que suelen hacer referencia a las formas de marcar una cita textual o incidir sobre algún aspecto del contenido del texto. En este sentido también es habitual encontrar citadas las fuentes con mezcla de caracteres visigóticos redondos y cursivos ${ }^{33}$.

Además de las anotaciones marginales y de las diferentes probationes pennae, se detectan en este ejemplar una serie de adiciones que no pertenecen a la obra original de san Gregorio. Se trata de los comentarios personales que incluyó Gómez, uno de los copistas del manuscrito, intercalándolos entre los explicit y los íncipit de algunos de los capítulos, y que consideramos importante reproducir para ofrecer algún dato más sobre los usus scribendi de este copista ${ }^{34}$, cuyo nombre es demasiado común en esos momentos. Los comentarios del escriba aparecen en tres ocasiones:

* f. 8ov. explicit-incipit, liber X, pars secunda:

¡O bone lector lectrixque, Gomiz peccatoris memento!

* f. Io6r. explicit-incipit, liber XIII, pars secunda:

Contuli diligentia qua potui quum/collectore sancto Pape Gregorii in Iob Moralia liber tertius decimus.

* f.I42r. explicit-incipit, liber XVI, pars III:

Quisquis hunc librum ob utilitatem tui legeres, ut ex eo edi/ficeris mei Gome[tachado: z] \sanis/peccatoris in tuis orationibus conmenda/tum habeto.

Como se puede comprobar, todos los comentarios hacen referencia a la salvación del alma de Gómez mediante su trabajo de diligente copista a través de la oración, y van dirigidos a los posibles lectores del códice ${ }^{35}$. Ahora bien, esto no significa

33. Además de los procesos de corrección mencionados es posible detectar diferentes marcas realizadas con posterioridad por diversas manos como son las pruebas de pluma y anotaciones en escritura gótica-humanística que, en un caso nada tienen que ver con el contenido del texto, así en el margen superior columna B del folio $247 v$ y en el mismo margen columna A del folio $248 \mathrm{r}$ aparecen las palabras: abad bal frezne h hansale/ fray yñigo ernando cascajales/ quintanjlla e mayo ojo mayo $1^{\circ}$ año 20 quandol hospital balbaricab que byllor qua/ fray christob[al] prio[r]; en el otro caso sí, ya que en el folio 6or repite con algún error de transcripción una línea de la columna B dónde dice: Aquila et enim/alto baldo bolatus/ suspenditus et et/ ad.....678 9 10/ nir [dibujo en forma de tótem]; también aparecen numerales arábigos en el margen superior del f. $44 \mathrm{r}$, posiblemente de la misma mano.

34. Puede compararse las fórmulas que utiliza Gómez con las que aparecen en textos contemporáneos expresadas por Endura y Florencio, véase GarcíA Molinos, Elena, Op. cit., pp. 365-371.

35. En este sentido se puede comprobar que las interpolaciones del escriba se producen en el mismo sentido sea cual fuere la parte del texto en que aparezcan, como ya explicara PETRUCCI, Armando para el caso de las suscripciones en códices del siglo $X$, «Las suscripciones que determinados escribanos introducían en los manuscritos, una vez acabado 
que el gusto por incluir este tipo de adiciones sea original de Gómez, más bien parece tratarse de indicaciones que se encontraban ya en la tradición textual ${ }^{36}$.

\section{LOS COPISTAS DE CÓDICE}

Según establece B. Shailor en su artículo, y repite la crítica especializada, son tres, al menos, las manos diferentes que intervienen en la copia de este códice de la obra de san Gregorio, además de las manos que, también en escritura visigótica, anotan el texto de alguna forma en los diferentes márgenes. La mano más experta es la del copista autodenominado Gómez diácono, ya que es el único que se permite interferir en el texto con sus comentarios y a él se debería el explicit del final del códice recogido por Berganza. Junto al primer copista se detecta una segunda mano, caracterizada en general por una mayor irregularidad gráfica, y sólo en el caso del folio 2I4 se podría establecer una tercera mano que añade también en visigótica, una importante laguna textual con alguna característica paleográfica que difiere de las otras dos manos.

Hasta aquí los datos que ofrece el estudio gráfico del manuscrito, ahora bien resulta discutible cómo se reparten el trabajo los dos primeros copistas, y si se puede aportar algún dato más sobre el copista III, si es que se puede demostrar su existencia.

El primer problema de adscripción de manos que plantea el texto va referido a ese supuesto segundo copista que escribe las partes del texto que no están realizadas por Gómez. Una vez analizada la división del códice a partir de las diferentes manos intervinientes según una determinada agrupación de folios y tras detectar que dichas adscripciones son insostenibles, lo que sí resulta posible establecer es que a lo largo de los numerosos folios que componen el manuscrito se observan determinados momentos en la escritura que conllevan algunas diferencias del estilo del copista, con respecto a la regularidad gráfica que define la escritura de Gómez. Así pues, existen dos tipos de variantes gráficas con respecto a las características paleográficas que hemos establecido como

el trabajo, ayuda a confirmar el hecho de que los copistas de la Alta Edad Media no tenían en su actividad preocupación algún a por la lectura -ni por los lectores-. Rara vez se dirigen a su interlocutor natural, el lector; y cuando lo hacen, no entran nunca en el diálogo [...]; la única pretensión claramente expresada, es la de obtener, a cambio del esfuerzo realizado, las oraciones necesarias para alcanzar la salvación de su alma», en «La lectura en la Edad Media», Irargi, 1988, pp. 293-314, trad. F. Gimeno Blay.

36. La antigüedad de este tipo de lugares comunes en las diferentes copias que pertenecen a la tradición vinculada con el texto de Tajón, ya la tuvo en cuenta Díaz y Díaz. Manuel Cecilio, Libros y librerías..., pp. 338-339 cuando apunta en una nota al pie refiriéndose al comentario del f. 106r. «lo que no admite discusión es que la nota se remonta a una colación antigua, aunque no puede establecerse con precisión su origen». De hecho, recoge como en el códice escurialense b.I.5. f. 158 aparece Contuli diligentia qua potui cum collectore sancti pape Gregorii Imo V Moralia. Sobre la comparación de estas fórmulas recurrentes también en las copias de Florencio de Valeránica véase GARCía MolinOS, Elena, Op. cit., pp. 365-371. En este trabajo no se recogen los comentarios que Gómez podría haber realizado en la suscripción por no conservarse en la actualidad. 
generales para la escritura del códice, que son las que definen la forma de escribir del copista mayoritario en el texto. La primera diferencia, y más abundante, consiste en un claro cambio del módulo de las letras, éste proviene de realizar las morfologías aisladas entre sí, con espacios en blanco ligeramente superiores y utilizar una caja de renglón apreciablemente más variable, lo que da a la escritura un aspecto de tamaño diferente al que utiliza Gómez, en ocasiones parece más grande y en otras inferior. La impresión visual es de una escritura dispersa y expandida a lo largo de la línea.

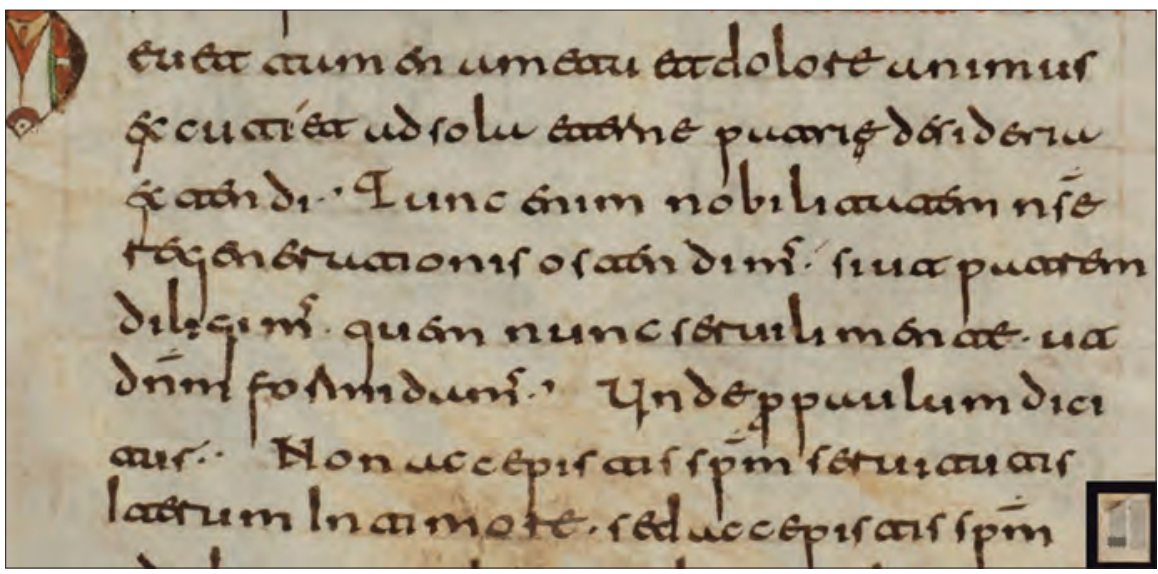

FIG. 2 F. 23V. COPISTA I (LÍNEAS 1-3 EXRTENDI. COPISTA II (LÍNEA 3 TUNC ENIM EN ADELANTE).

(C) John Rylands Library, Manchester.

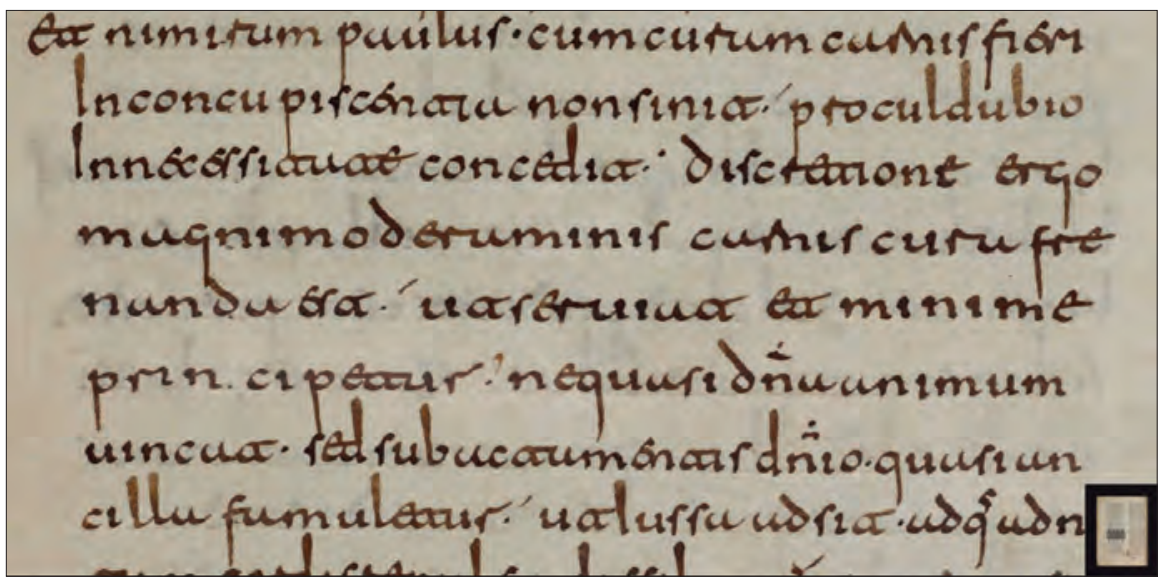

FIG. 3 F. 69V. COPISTA I (LÍNEAS 1-3). COPISTA II (LÍNEA 4-7 UINCAT). C John Rylands Library, Manchester.

Las intervenciones de esta mano se realizan de forma constante en diversos fragmentos del códice, generalmente enmarcados por signos de puntuación. Es cierto que sólo un cambio en el módulo de la escritura podría no ser suficiente para justificar un cambio de mano, pero en este caso debido a la cantidad de 
fragmentos localizados con las mismas características gráficas intercalados a lo largo del texto, hacen pensar en una segunda mano que interviene alternando su trabajo con el de Gómez, aunque sus intervenciones no contengan una cantidad de texto equivalente al del primer copista, porque cuesta pensar que un mismo copista realice estos cambios gráficos de forma regular sin motivo alguno ${ }^{37}$.

La segunda variante se puede detectar en otro pequeño grupo de intervenciones gráficas, mucho menor cuantitativamente que el caso anterior, que interviene en el proceso de copia de forma mucho más puntual, realizando como mucho un par de líneas cuya destreza gráfica es menor que la de los copistas anteriores, bien por falta de práctica o bien porque sus características físicas influyan. Este copista comparte las características generales de la visigótica redonda de principios del siglo X con sus compañeros, pero la irregularidad en el trazo es mucho mayor, lo que le lleva a no respetar la línea de renglón, ya que las letras no descansan en ella de forma regular, así como a alterar el tamaño habitual de las morfologías realizando diferentes tamaños dentro de una misma palabra (es el caso de la letra $o$ de tamaño muy inferior al habitual). Además, marca un ángulo de inclinación hacia la derecha o la izquierda, frente a la marcada verticalidad de los copistas anteriores; incluso la punta de su instrumento escriptorio, quizás peor afilada, produce trazos de diferente grosor, sobre todo en astiles. Ahora bien, estos cambios gráficos podrían deberse a una intervención posterior a la copia del códice que viendo el hueco en blanco que conlleva la falta de frases o palabras, decide completar el texto más preocupado quizás por el contenido de la obra que por mantener una similitud gráfica con el resto de la copia.

No podemos olvidar que una mano diferente añadió las lagunas del texto que procedían de los errores de copia y otras manos, también posteriores, añadieron las fuentes religiosas y patrísticas que componen el texto a lo largo de todo el manuscrito, aunque no de forma rigurosa, en los diferentes márgenes o en el intercolumnio ${ }^{38}$.

37. La identidad de este segundo copista no está aclarada, ya que se conocen copistas posteriores que trabajaron en san Pedro de Cardeña, pero que en el año 914 aún no habían nacido (Endura, Sebastián o Diego), véase GARCíA Molinos, Elena, Op. cit., pp. 243-259 y Pérez de URBEL, Justo, Cardeña y sus escribas..., pp. 217-236. Por lo que se refiere a la intervención de copistas alternantes, véase el excelente trabajo de Herrero de la FuenTE, Marta y Fernández FLóREZ, José Antonio, «Sobre la escritura visigótica el León y Castilla durante su etapa primitiva (siglos VII-X): algunas reflexiones», en La escritura visigótica en la Península Ibérica: nuevas aportaciones, Universidad Autónoma de Barcelona, Bellaterra, 2012, pp. 55-104, donde explican: «queremos recordar nuestro estudio sobre el Albeldense de los concilios, que nos llevó a descubrir la presencia de dos manos en su elaboración, con más de ochenta intervenciones por parte de cada una de ellas; lo que, de paso nos venía a confirmar la intervención alternativa y, por tanto, la coexistencia en un mismo scriptorium, de dos copistas con similares habilidades en la ejecución de la escritura visigótica redonda», p. 96.

38. Shallor, Barbara, op. cit., p. 464 una vez atribuido al copista Aeximinus el f. 214, propone la siguiente reconstrucción de los primeros momentos de existencia del Ms. Lat. 83: «Sometime after the completion of the codex in 914 by Gomez and Scribe II the manuscript was demaged and a portion of the text was either mutilated or lost. Aeximinus, a Scribe at Cardeña in the secord third of the tenth century, was given the task of supplying the text». Para que dicha reconstrucción fuera plausible, Eximeno tendría que haber copiado no sólo el folio 214 sino todas las faltas que nos encontramos poblando los márgenes inferiores del manuscrito, lo cual, como ya se ha explicado, no parece que cuente con el apoyo paleográfico, ya que son varias la manos diferentes que intervienen en el proceso de completar el texto. 


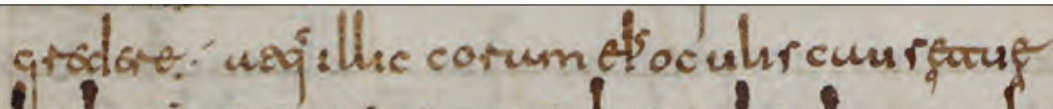

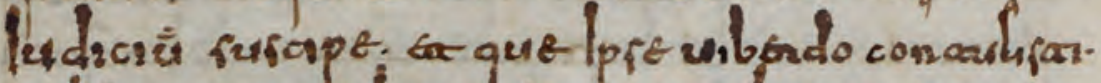

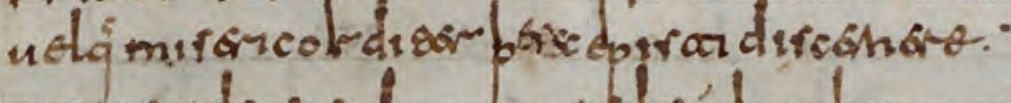
eacuneuderperduesum rads. dumbonu aci
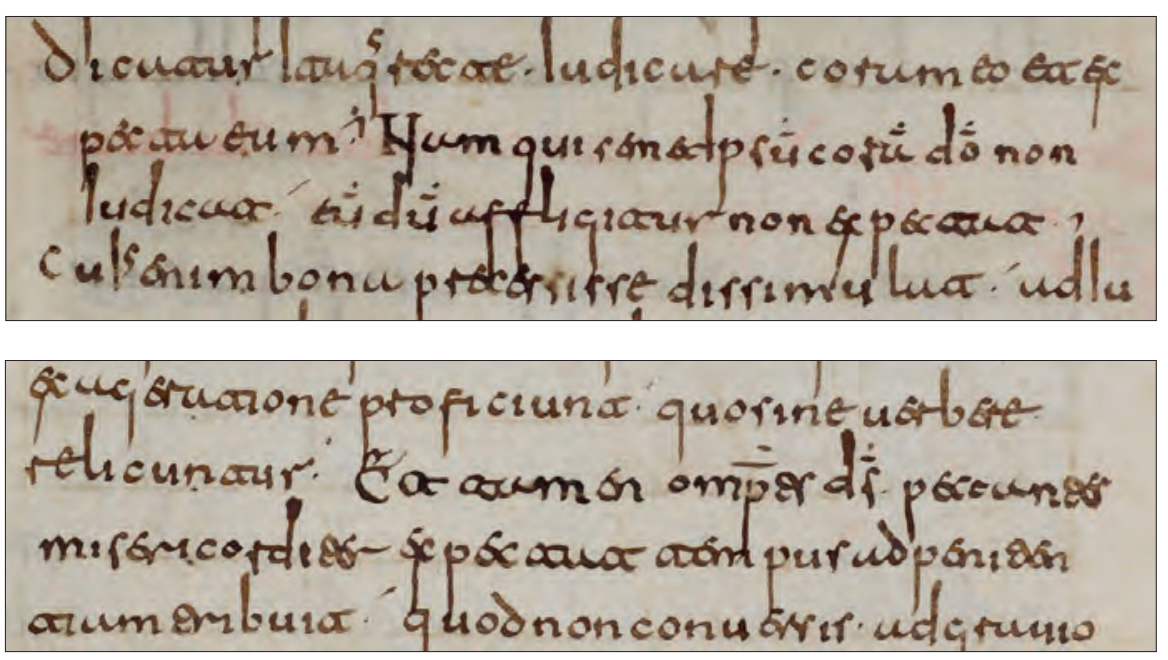

FIG. 4. F. 25IV. COPISTA III. IMAGEN I(LÍNEAS 2-3). IMAGEN 2 (LÍNEA 2 NAM ...-3). IMAGEN 3 (LÍNEA 2 ET ...3 MISERICORDITER. (C) John Rylands Library, Manchester.

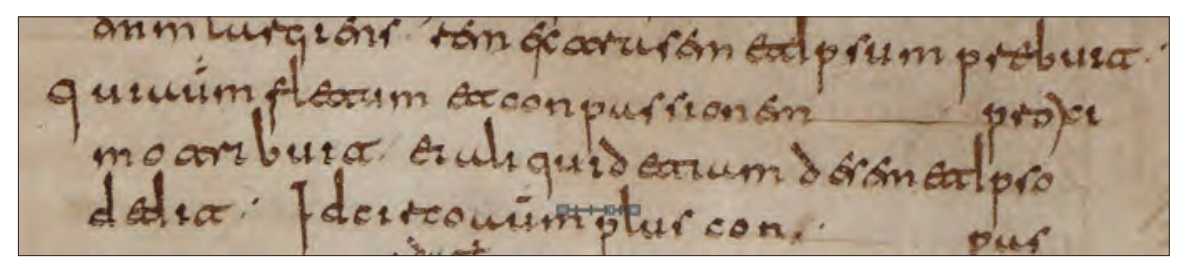

FIG. 5 F. 194V. HUECOS EN BLANCO. (C) John Rylands Library, Manchester.

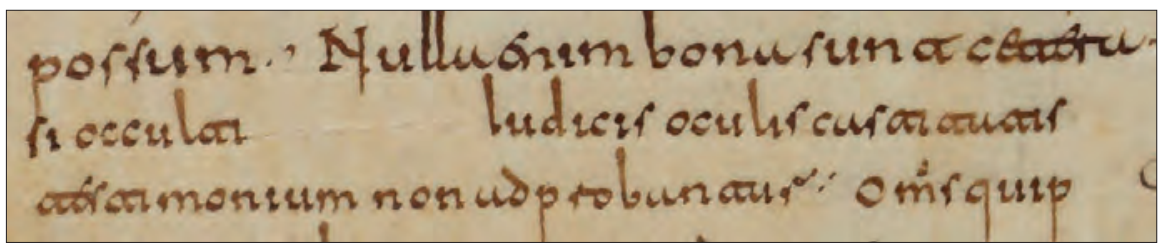

FIG. 6 F. 198R. CAMBIO DE MÓDULO, CON HUECO EN BLANCO. (C) John Rylands Library, Manchester. 
La tercera mano interviniente, según la distribución establecida por B. Shailor, cuya importancia radica en haber añadido el folio 2I4 para intentar paliar una falta de texto muy extensa con respecto a la obra de san Gregorio, es la que se atribuye a un copista de Cardeña, Aeximinus, que ejerció su labor años después de que se diera por finalizada la copia de los Moralia. Desde el punto de vista de los usos escriptorios, este supuesto tercer copista tan sólo se diferencia en tres cuestiones con respecto a los mismos usos en el resto del códice: utiliza una fórmula para el explicit más breve («Explicit liber XXII. Deo gratias»), el folio escrito por él tiene una columna A de 46 líneas y una B de 47, esta segunda opción es la habitual en el códice, y utiliza claramente la forma asibilada tj, ya que de 16 casos detectados marca la diferencia gráfica en 15 . No existe ningún aspecto codicológico o gráfico más que pueda hacer pensar en un escriba diferente a los anteriores, ya que cualquiera de las cuestiones paleográficas que hemos establecido para el resto de folios se pueden aplicar del mismo modo al folio $2 \mathrm{I}^{39}$, excepto el cambio en el gusto por marcar los fenómenos t+yod. Creo, por tanto, que no es necesario complicar el proceso que podría describir cómo se añadió este folio al manuscrito, ya que pudo realizarse una vez finalizado el proceso de copia inicial, pocos años después, por el propio Gómez, que quizás durante el periodo de transición en el que lo escribió ya se habría rendido a las formas más modernas del uso de tj y de la doble curva frente al semicolon para marcar la suspensión de -us, ya que, además, en ningún caso, el folio $2 \mathrm{I} 4$ marca la frontera de diferentes tipos de escritura visigótica en el manuscrito, como se había propuesto ${ }^{40}$.

Ahora bien, el texto añadido en el folio 2I4 no da cuenta de la totalidad de la parte que falta de la obra de san Gregorio. Gómez había dejado de escribir en lo que él consideró el final del libro XXIl y, por tanto, de la parte cuarta. Pues bien, cotejado el texto que aporta dicho folio con la edición de la obra que contiene la Patrologia Latina, dicho folio copia una vez ya comenzado el libro XXIII y hasta el final de la parte cuarta de la obra. Pero, desde el final del folio 2I3v de Gómez, hasta que comienza el texto añadido en el folio $2 \mathrm{I} 4$ falta la mayor parte del libro XXII y el comienzo del libro XXIII, cuya equivalencia aproximada en cantidad de texto escrito, se correspondería con algo más de una columna ${ }^{41}$. Esta laguna

39. Las características generales que estableció LoWE, Elias Avery, Op. cit., p. 61 para este manuscrito atendiendo a las formas gráficas de Gómez, son del todo compatibles con las que presenta el folio 214, como puede observarse: «The script is looser and larger; the shafts of tale letters are club-shaped; the shaftless letters have more height than breadth. The final stroke of $m, n, h$, often turns out. The separation of words is more distinct; the interrogation point is used. The suspensions 'bus' and 'que' are represented now by means of the semi-colon, now by means of an s-like flourish».

40. En este sentido ya se manifestó PÉREZ de URBEL, Justo en su artículo «Cardeña y sus escribas durante la primera mitad del siglo X», Bivium; Homenaje a M.C. Díaz y Díaz, Madrid, Gredos, 1983, 217-238, cuando al reflexionar sobre el uso de la forma ti escribe: «Gómez emplea siempre $t$, pero se da el caso de que un corrector se entretuvo en alargar el rasgo de la $i$, cuando $t i$, seguido de otra vocal, debía pronunciarse zi ¿sería el mismo Gómez el que realizó esta tarea cuando tuvo noticia de esta novedad que no tardó en difundirse por toda Castilla?», p. 222.

41. Según la edición de los Moralia que recoge Migne dicha falta se correspondería con el v. 76, col. 246-247, desde 31, 39, XXII, 53 hasta 31,39, XXIII, 54, «[cap. XXII] ... De qua videlicet predicatione [... cap. XXIII] praedicator optat, si fieri valeat». 
textual parece claramente que obedece a un proceso de copia, relacionado o no, con un error por homoioteleutón, más difícil resulta suponer que hace referencia a un modelo textual que careciera de dicha parte ${ }^{42}$.

No me parece necesario, por tanto, adjudicar el folio $2 \mathrm{I} 4$ a un copista diferente a los ya propuestos para el resto del texto, sino más bien a un momento posterior de copia revisada por el mismo escriba que realizó la mayor parte del códice ${ }^{43}$.

Es frecuente encontrar entre los trabajos de la crítica especializada la propuesta de que los Moralia in Iob que realiza Florencio de Valeránica en el año 945 tienen como modelo la obra de san Gregorio que realizara Gómez en Cardeña en el año 9I4 ${ }^{44}$. Después de analizar los datos que aporta el folio 2I4 se puede afirmar que esta intuición no tiene base textual alguna. Como ya hemos explicado, al texto de Gómez le faltan numerosos fragmentos, hasta el punto de que algún escriba decide añadir parte de ese contenido en el folio 2I4, pero entre el texto copiado por Gómez y el añadido del folio 2I4 sigue faltando parte de los libros XXII y XXIII. Una vez cotejado el texto copiado en el año 9I4, incluido el añadido del folio, con el que se realiza en el año 945, se puede observar que en el manuscrito que lleva a cabo Florencio sí aparece copiada la laguna textual de forma íntegra que hemos establecido en esa parte del texto (f. $314 \mathrm{v}^{\mathrm{b}}-3 \mathrm{I} 5 \mathrm{r}^{\mathrm{a}}$ hasta la línea número 20). Esas 63 líneas Florencio no las pudo copiar de Gómez, porque en su manuscrito no están. Además, en el folio 2I3v del Ms. Lat. 83 se produjo uno de los errores

42. García Molinos, Elena, en el excelente artículo posterior a su tésis «Florencio de Valeránica, caligráfo y notario del siglo X», El reino de León en la Edad Media, centro de Estudios e Investigación san Isidoro, León, 2004, pp. 241-431, además de explicar cómo está construida la versión de los Moralia de san Gregorio que se copia en la Península, redoge la dos tradiciones textuales diferentes que existieron durante la edad media, una que se copiaría con textos introductorios (dos prólogos atribuidos a san Jerónimo, un sumario del libro de Job, una carta del obispo Tajón de Zaragoza, una leyenda de la pérdida de los libros, el elenco de las obras de san Gregorio y una copia del De uiris illustribus de san Isidoro), a este grupo pertenecería el texto mancusiano, y otra tradición sin textos añadidos y sin divisiones en seis partes. Esta doble posibilidad, en cualquier caso, no justifica las numerosas faltas de texto de nuestro manuscrito. Sobre la pertenencia del códice a la tradición tajoniana véase, DíAz y DíAz, Manuel Cecilio, Códices visigóticos en la monarquía leonesa, León, 1983, p. 334.

43. Para adjudicar, como hace B. Shailor, a Aeximinus la copia de dicho folio haría falta poder establecer características más claras de las particularidades gráficas de su escritura para compararlas con la escritura de otros testimonios llevados a cabo por este escriba, ya que sólo el uso de tj como única diferencia gráfica resulta excesivo para adscribir este folio a un copista diferente a los ya intervinientes. Incluso LowE, Elias Avery, Op. cit., p. 59 explica cómo desde la mitad del siglo IX hasta la mitad del siglo X unos escribas realizan la distinción y otros no, amén de que hay escribas que la realizan en unos casos sí y en otros no. Es por tanto arriesgada la conclusion a la que llega SHAILOR, Barbara, Op. cit., p. 464, cuando aclara:» Folio 214 is interesting for a second reason: it contributes to our knowledge of scribal practices in the scriptorium. The folio offers the earliest evidence from Cardeña for the graphic distinction between assibilated and unassibilated ti». Además, en trabajos que estudian el tema de los copistas en monasterios burgaleses del siglo X, no afirman que Eximeno formara parte del elenco de escribas de Cardeña en dicho siglo, véase GARCíA MoLINOS, Elena, Op. cit., pp. 241-259 y PÉREZ de URBEL, Justo, «Cardeña y sus escribas...», pp. 217-236, dónde se constata su presencia como colaborador de Florencio en San Pedro de Valeráncia. Su paso, pues, por Cardeña en el 914 se plantea como una posibilidad, véase también Pérez de URBEL, Justo, «El escriba Eximeno ...», p. 83.

44. La dependencia textual de ambos códices aparece recogida en los estudios ya mencionados de García Molinos, Elena, op. cit., p. 275, PÉREZ de URBEL, Justo, «Cardeña y sus escribas...», p. 235, así como en el de EsCALONA, Julio, VeLÁZqUeZ SORIANO, Isabel JUÁREZ BENíteZ, Paloma,»Identification of the sole extant original chárter by Fernán González, Count of Castile (932-970)», Journal of Medieval Iberian Sutdies, v. 4, n. 2, 2012, 259-288, en la página 278, n, 51; entre otros. 
por homoioteleutón, o salto en la copia ${ }^{45}$, a los que ya nos hemos referido en otras partes de este trabajo, pues bien, también existe una variante textual en el manuscrito de Florencio con respecto al copista que añade dicha inserción en el manuscrito de Gómez, así donde el corrector de Gómez copia lectjonis, Florencio escribe lectjo. A pesar de la cercanía geográfica y cronológica de ambos códices, el segundo no pudo ser copia del primero, sino de algún otro ejemplar que siguió la misma división textual y que contenía también los textos iniciales, y que formaría parte de una misma rama de la transmisión textual de la obra.

Con respecto al controvertido folio 2I4 es también reseñable un aspecto que corresponde a la tradición textual posterior del códice. A pesar de no haber copiado completo todo el fragmento que faltaba de la obra de san Gregorio, el copista de dicho folio dejó en blanco todo el f. 2I4v, excepto siete líneas, lo que nos aclara la voluntariedad de dicha falta. Un hueco en blanco de material escriptorio de este tamaño debía resultar aprovechable, porque en el siglo XII un escriba/iluminador lo utiliza para realizar una representación iconográfica de la rueda de la fortuna en rojo y negro, donde junto a la diosa Fortuna aparecen unos personajes (reyes) con las leyendas: regno, regnabo, renauj, sum sine regno, que colocados encima de la rueda a modo de noria son movidos mediante una manivela por la diosa ${ }^{46}$. A esta misma mano se deben también un conjunto de manchas rojas que aparecen diseminadas por el manuscrito a modo de rozaduras.

Es necesario concluir, por tanto, según hemos expuesto en el presente trabajo, que, puesto que contamos con un corpus establecido de manuscritos visigóticos del que partir gracias al enorme esfuerzo de anteriores especialistas, se impone cada vez más realizar una revisión singularizada de dichos manuscritos medievales. Sólo así se podrán aportar nuevos datos, o refrendar la información que ofrecen las fuentes bibliográficas, sobre los usos paleográficos y codicológicos en la Alta Edad Media.

45. Se produce en el folio $213 \mathrm{~V}$ cuando el copista finaliza la columna A en las palabras parit et sunt y la siguiente palabra en la copia es non nulli. Quien continúa copiando no se da cuenta de que esta misma forma aparece en dos ocasiones en cuatro líneas, por lo que sigue copiando desde la segunda, saltándose así las líneas intermedias entre la primera vez que aparece non nulli y la segunda.

46. Sobre las representaciones iconográficas de la rueda de la Fortuna en la Edad Media entre los siglos XI al XIV véase, SÁNCHEZ MÁrquez, Carles, «Fortuna velut luna»: iconografía de la Rueda de la Fortuna en la Edad Media y el Renacimiento», eHumanista, 17, 2011, pp. 230-253. En este trabajo aparece recogido el dibujo incluido en el Ms. Lat. 83 (Figura 3. Rueda de la Fortuna. Miniatura del siglo XII, p. 243), de la que tan sólo aclara que es «el caso de una miniatura del siglo XII (procedencia desconocida), donde hallamos nuevamente a la Fortuna, provista de rueda, corona y espada, accionando la rueda», p. 235 


\section{BIBLIOGRAFÍA CITADA}

Avrıl, François; AnıEl, Jean-Pierre; Mentré, Mireille; SAUlnier, Alix; Zaluska, Yolanta (I982), Manuscrits enluminés de la Péninsule Ibérique, Bibliothéque Nationale, París.

Adriaen, Marci (ed.) (I979-I985), S. Gregorii Magni, Moralia in Iob, Turnholti, Brepols, vol. I-III.

Berganza y Arce, Francisco de (I72I), Antigüedades de España, Madrid, vol. I, pp. I77-I78 y vol. II, pp. 578-590.

Bustos Tovar, José Jesús de (2013), La escisión latín-romance. El nacimiento de las lenguas romances: el Castellano, en Cano, Rafael (coord.), Historia de la lengua española, Madrid, Ariel, pp. 259-290.

CAMINo MARTínez, Carmen del (I990), Los orígenes de la escritura visigótica: ¿otras posibilidades para sus estudio?, en Actas del VIII Coloquio del Comité Internacional de Paleografía latina, Madrid, Joyas Bibliográficas, pp. 29-37.

CANELlas LóPEZ, Ángel (1990), Algunos membra disiecta en visigótica sentada pirenáica, con fragmentos de las Collationes Cassiani, del siglo X, en Actas del VIII Coloquio del Comité Internacional de Paleografía latina, Madrid, Joyas Bibliográfica, pp. 39-50.

DíAz y DíAz, Manuel Cecilio (I983), Códices visigóticos en la monarquía leonesa, León, CSIC Instituto de Estudios Riojanos.

DíAz y Díaz, Manuel Cecilio (I99I), Libros y librerías en la Rioja altomedieval, Logroño.

Dufell, Michel-Marie (1988) Du couchant des Orients à l'Azur de l'Europe en Les couleurs au Moyen Âge, Presses universitaires de Provence, Aix-en-Provence, pp. 87-Io8.

Escalona, Julio; Velázquez Soriano, Isabel; Juárez Benítez, Paloma (20I2), Identification of the sole extant original chárter by Fernán González, Count of Castile (932-970), «Journal of Medieval Iberian Studies» 4/2, pp. 259-288.

FernÁNdez Flórez, José Antonio (I997), Escribir, en León-Castilla, en la época medieval. Viajes y viajeros en la España medieval, Aguilar de Campoo- Madrid, Fundación Santa María la Real-Ediciones Polifemo, pp. I45-I75.

García Molinos, Elena (2004), Florencio de Valeránica, caligráfo y notario del siglo X, en $E l$ reino de León en la Edad Media, León, Centro de Estudios e Investigación san Isidoro.

Gil, Juan (20I3), El latín tardío y medieval (siglos VIII-XIII), en Cano, Rafael, Historia de la lengua española, Madrid, Ariel, pp. I49-I8o

Gousset, Marie-Thérèse; Stirnemann, Patricia (i990), Indications de couleur dans les manuscrits médiévaux, en Pigments and colorants de l'Antiquité et du Moyen Âge, Colloque international du CNRS, Editions du Centro National de la Recherche Scientifique, París, pp. I89-I98.

Herrero de la Fuente, Marta; Fernández Flórez, José Antonio (20I2), Sobre la escritura visigótica en León y Castilla durante su etapa primitiva (siglos VII-X): algunas reflexiones, en La escritura visigótica en la Península Ibérica: nuevas aportaciones, Bellaterra, Universidad Autónoma de Barcelona, pp. 55-I04.

James, Montague Rhodes; TAYLOR, Frank (ed.) (1980), A Descriptive Catalogue of the Latin Manuscripts in the John Rylands Library at Manchester, Manchester, University Press, vol. I, pp. 150-152.

Lowe, Elias Avery (1972), Palaeographical papers 1907-1965, Oxford.

MenÉndez Pidal, Ramón (I999), Manual de gramática histórica española, Madrid, Espasa-Calpe.

Migne, Jacques Paul (ed.) (1857-I862), Patrologiae Cursus Completus. Series Latina, París, vol. LXXV, pp. 509-II6I, vol. LXXVI, pp. 9-78I. 
Millares Carlo, Agustín (I999), Corpus de códices visigóticos, Canarias, Gobierno de Canarias, vol. I.

Pastoureau, Michel (2010), Azul. Historia de un color, Barcelona-Buenos Aires, Paidós.

Pérez de Urbel, Justo (I977), El escriba Eximeno y los comienzos del escritorio de San Millán de la Cogolla, «Boletín de la Institución Fernán González» 56/188, pp. 75-95.

Pérez de Urbel, Justo (I983), Cardeña y sus escribas durante la primera mitad del siglo X, en Bivium; Homenaje a M.C. Díaz y Díaz, Madrid, Gredos, pp. 217-236.

Petrucci, Armando (I988), La lectura en la Edad Media, «Irargi», I, pp. 293-3I4.

QuiÑones Costa, Ana María (1992), La decoración vegetal en el Arte Español de la Alta Edad Media: su simbolismo, Madrid, Universidad Complutense de Madrid, (tesis doctoral).

Ruiz Asencio, José Manuel (1987), Documentos y códices altomedievales de San Román de Entrepeñas en Actas del I congreso de Historia de Palencia, II: Fuentes documentales y Edad Media, Palencia, pp. 9-50.

SÁNCHEZ MÁrquez, Carles (20II), «Fortuna velut luna»: iconografía de la Rueda de la Fortuna en la Edad Media y el Renacimiento, «eHumanista», I7, pp. 230-253.

SHAIlor, Barbara A., (I979), The scriptorium of San Pedro de Cardeña, «The Bulletin John Rylands Library», Manchester, pp. 444-473. 

Calidad de Revistas

científicas Españolas

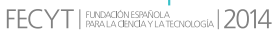

SERIE III HISTORIA MEDIEVAL

REVISTA DE LA FACULTAD DE GEOGRAFÍA E HISTORIA
AÑO 2018

ISSN: 0214-9745

E-ISSN 2340-1362

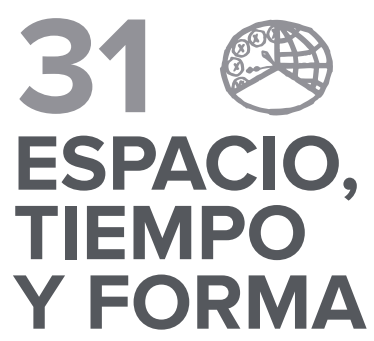

GREGoRIO DEL SER QUIJANO

Carmelo Luis López, In Memoriam

\section{Artículos · Articles}

29 SOHA ABBOUd Haggar

Un resumen del tratado jurídico de Al-Tafrí: el Manuscrito Árabe 1233 del Monasterio de El Escorial y su supuesta relación con Leyes de Moros

EDUARDo Aznar VALLejo

Norma y conflicto en la navegación castellana bajomedieval

69 Carlos Barquero Goñ

Transferencias de recursos de la Orden de San Juan desde España hasta el Mediterráneo Oriental durante la Edad Media

\section{Margarita Cabrera Sánchez}

La muerte del príncipe Don Juan. Exequias y duelo en Córdoba y Sevilla durante el otoño de 1497

\section{Francisco de Paula Cañas Gálvez}

Primogenitura, continuidad dinástica y legitimitad instituciona en Castilla a principios del siglo XV: Catalina de Trastámara, Princesa de Asturias (1422-†1424)

\section{Paloma Cuenca Muñoz}

El códice visigótico de los Moralia in lob, ms. lat. 83 de la John Rylands Library de Manchester

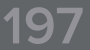

\section{JOSÉ MARÍA DIAGO JIMÉNEZ}

Las instituciones educativas de carácter religioso en el reino hispanovisigodo de los siglos VI y VII a través de los cánones conciliares y las reglas monásticas

MARÍA Díez Yáñez

La Ética aristotélica en Castilla: las bibliotecas universitarias medievales y prerrenacentistas

\section{Estefanía Ferrer del Río}

Rodrigo de Mendoza, I Marqués del Cenete y I Conde del Cid: paralelismos entre su biografía y su pretendida genealogía

\section{ALEJANDRo García Morilla \\ Escritura publicitaria de transición: entre la visigótica y la carolina.} El paradigma burgalés

María Dolores García Oliva

Señores contra campesinos: un conflicto por la tierra en Mirabel a finales de la Edad Media y principios de los Tiempos Modernos (1488-c. 1520)
343 JaIme García Carpintero López de Mota

La hospitalidad santiaguista a finales de la Edad Media: el proyecto de reconstrucción del hospital de Alarcón

377 LAURA DA GRACIA

La posesión agraria individual en los registros notariales de Fuente el Sol (1481-1482

4.03 Mauricio Herrero Jiménez

El valor de los documentos reales en los procesos de la Real Chancillería de Valladolid

431 Miguel josé López-Guadalupe Pallarés

Procesos de señorialización en los concejos de la Extremadura castellano-leonesa. Un estado de la cuestión

455 Ángel Martínez Catalán

Las rentas decimales del cabildo catedralicio de Cuenca a inicios del siglo XV (1400-1432)

4.83 Gonzalo Oliva Manso

Cien años de moneda en Castilla (1172-1268). El siglo del maravedí de oro

521 jesús Olivet García-Dorado

El cabildo de curas y beneficiados de Toledo en la segunda mitad del siglo XV. Composición y aspectos institucionales (1455-1488)

547 Mariel PÉrez

Clérigos rurales, comunidades y formación de las estructuras parroquiales en la diócesis de León (siglos XI-XIII)

575 Milagros Plaza Pedroche

La Orden de Calatrava en la Baja Edad Media (1350-1500): repaso historiográfico

597 Pedro Andrés Porras Arboledas

La pervivencia del Fuero de Cuenca en los inicios de la Modernidad: el testimonio de los fueros de Consuegra y Requena

619 Juan Pablo Rubio Sadia

Los mozárabes frente al rito romano: balance historiográfico de una relación polémica

SANDRA SUÁREZ GARCíA

Los habices de la Vega de Granada como forma de conocimiento del reino nazarí y su transformación tras la conquista: la alquería de La Zubia 


\section{1}

\section{ESPACIO,}

\section{TIEMPO}

\section{Y FORMA}

SERIE III HISTORIA MEDIEVAL

REVISTA DE LA FACULTAD DE GEOGRAFÍA E HISTORIA

\section{De medievalistas ilustres · On Renowned Medievalists}

671 Francisco Abad Nebot

Entradas para un Diccionario

\section{Libros $\cdot$ Books}

679 Almagro Vidal, Clara, Paisajes medievales en el Campo de Calatrava (CARLos BARQUero GoÑI)

681 Carvajal Castro, Álvaro, Bajo la máscara del Regnum. La monarquía asturleonesa en León (854-1037) (JOSÉ MANUEL RODRÍGUEZ GARCíA)

683 Fuente Pérez, María Jesús, Violante de Aragón, reina de Castilla (ANA ECHEVARRía ARsuaga)

687 Martín Prieto, Pablo, Historia del pensamiento medieval: filosofia y teología (FRANCISCO LEÓN FLORIDO)

689 Pardo de Guevara y Valdés, Eduardo (ed.), Mujeres con poder en la Galiciamedieval (siglos XIII-XV). Estudios, biografías y documentos (ENRIQUE CANTERA MONTENEGRO)

693 Ríos Saloma, Martín (ed.), El mundo de los conquistadores (Jessica Ramírez MéndeZ)

690 Solórzano Telechea, Jesús, Arízaga Bolumburu, Beatriz y BOCHACA, Michel (eds.), Las sociedades portuarias de la Europa atlántica en la Edad Media (ANTONIO ORTEGA VILLOSLADA)

703 VAL VALDIVIEso, María Isabel del (coord.), El agua en el
imaginario medieval. Los reinos ibéricos en la Baja Edad Media (MARÍA Jesús Fuente)

707 Villar García, Luis Miguel, Archivo Municipal de Segovia. Documentación medieval, 1166-1474 (ENRIQUE CANTERA MONTENEGRO) 